\title{
๑The Impact of Overturning and Horizontal Circulation in Pine Island Trough on Ice Shelf Melt in the Eastern Amundsen Sea
}

\author{
BENJAMIN G. M. WEBBER \\ Climatic Research Unit, Centre for Ocean and Atmospheric Sciences, School of \\ Environmental Sciences, University of East Anglia, Norwich, United Kingdom \\ KAREN J. HEYWOOD \\ Centre for Ocean and Atmospheric Sciences, School of Environmental Sciences, \\ University of East Anglia, Norwich, United Kingdom \\ DAVID P. STEVENS \\ School of Mathematics, University of East Anglia, Norwich, United Kingdom \\ KAREN M. ASSMANN \\ Department of Marine Sciences, University of Gothenburg, Gothenburg, Sweden
}

(Manuscript received 12 October 2017, in final form 12 September 2018)

\begin{abstract}
The ice shelves around the Amundsen Sea are rapidly melting as a result of the circulation of relatively warm ocean water into their cavities. However, little is known about the processes that determine the variability of this circulation. Here we use an ocean circulation model to diagnose the relative importance of horizontal and vertical (overturning) circulation within Pine Island Trough, leading to Pine Island and Thwaites ice shelves. We show that melt rates and southward Circumpolar Deep Water (CDW) transports covary over large parts of the continental shelf at interannual to decadal time scales. The dominant external forcing mechanism for this variability is Ekman pumping and suction on the continental shelf and at the shelf break, in agreement with previous studies. At the continental shelf break, the southward transport of CDW and heat is predominantly barotropic. Farther south within Pine Island Trough, northward and southward barotropic heat transports largely cancel, and the majority of the net southward temperature transport is facilitated by baroclinic and overturning circulations. The overturning circulation is related to water mass transformation and buoyancy gain on the shelf that is primarily facilitated by freshwater input from basal melting.
\end{abstract}

\section{Introduction}

The ice shelves around the Amundsen Sea are some of the fastest melting in Antarctica (Rignot et al. 2013), owing to a combination of bedrock that deepens inland (Favier et al. 2014; Christianson et al. 2016) and basal melt driven by the circulation of warm Circumpolar Deep Water (CDW) onto the continental shelf (e.g., Jacobs et al. 2011). CDW enters the shelf through the eastern trough $(\mathrm{ET})$ at $71.5^{\circ} \mathrm{S}, 102^{\circ}-108^{\circ} \mathrm{W}$ and the

¿ Denotes content that is immediately available upon publication as open access.

Corresponding author: Benjamin Webber, b.webber@uea.ac.uk central trough $(\mathrm{CT})$ at $71.5^{\circ} \mathrm{S}, 113^{\circ} \mathrm{W}$ and then merges and continues southward toward Pine Island and Thwaites ice shelves along the eastern edge of Pine Island Trough (Heywood et al. 2016). This water loses heat to melting the glaciers before flowing northward along the western edge of Pine Island Trough and then westward toward the Ross Sea as a cooler and fresher water mass (Nakayama et al. 2013, 2014a; Biddle et al. 2017; Mallett et al. 2018).

The oceanic conditions on the Amundsen Sea continental shelf vary on a range of time scales. There is a seasonal cycle with the thickest CDW layer found in

This article is licensed under a Creative Commons Attribution 4.0 license (http://creativecommons. org/licenses/by/4.0/). 
August-October in Pine Island Trough (Kimura et al. 2017). At interannual time scales, both the thermocline depth (Dutrieux et al. 2014) and circulation strength (Jacobs et al. 2011) vary considerably, linked to both tropical (Steig et al. 2012; Dutrieux et al. 2014) and local (St-Laurent et al. 2015; Webber et al. 2017) forcing. Jenkins et al. (2016) combined models with the relatively sparse observational record and found some evidence for decadal variability, possibly forced from the tropics, but little evidence of any long-term trend in ocean temperature. Here we focus on the interannual to decadal variability as this is relatively poorly constrained and dominant in many time series. Furthermore, glacial modeling suggests that ice streams in West Antarctica are particularly sensitive to decadal variability in ocean heat fluxes (Snow et al. 2017).

The vertical structure of the heat transport onto the shelf is uncertain, with studies disagreeing as to whether the most important flux of heat is carried by baroclinic (Arneborg et al. 2012; Wåhlin et al. 2013) or barotropic (Kalén et al. 2016) currents. Thurnherr et al. (2014) found a clockwise horizontal gyre of $1.5 \mathrm{~Sv}\left(1 \mathrm{~Sv} \equiv 10^{6} \mathrm{~m}^{3} \mathrm{~s}^{-1}\right)$ flowing around Pine Island Bay, while Schodlok et al. (2012) showed that variability in the wider barotropic circulation around the Amundsen Sea is correlated with temperature within the Pine Island ice shelf cavity. Within this cavity there is a combination of horizontal and vertical circulation, the variability of which is linked to the melt rate (Jacobs et al. 2011; Dutrieux et al. 2014). In an idealized simulation under climate change conditions it has been shown that the overturning circulation induced by the melt rate can act as a positive feedback, by increasing the onshore transport of CDW (Donat-Magnin et al. 2017). Jourdain et al. (2017) showed that melting within ice shelf cavities in the Amundsen Sea strengthens the circulation, bringing in more heat than required for melting, and that this drives an important pump of heat from the deep ocean to the near surface. Despite these recent advances, the interannual variability of the overturning within Pine Island Trough and its relation to the flow of CDW around the Amundsen Sea continental shelf have not been quantified.

This study uses a regional numerical model to investigate the relative importance of the horizontal and overturning components of the circulation in bringing CDW to the cavities of the Pine Island and Thwaites ice shelves. The model description, validation, and description of the calculation of temperature transports and overturning streamfunction are given in section 2 . We initially discuss the time-mean circulation of the model, including the flux of temperature and CDW around the continental shelf (section 3a) and the overturning circulation (section $3 \mathrm{~b}$ ). We then focus on the interannual variability in the model run, starting with the variability in temperature transports around the continental shelf (section 3c), followed by variability in the overturning circulation and CDW transports (section 3d). We examine correlations with external forcings in section $3 \mathrm{e}$, followed by a discussion (section 4) and summary (section 5).

\section{Model and methods}

\section{a. Model description}

We use a regional setup of the MITgcm (Marshall et al. 1997) model that simulates sea ice (Losch et al. 2010) and ice-ocean interaction in ice shelf cavities (Losch 2008). The model is as described by Assmann et al. (2013), with horizontal resolution of $0.1^{\circ}$ longitude and $0.1^{\circ} \times \cos (\phi)$ latitude over the domain of $76^{\circ}-62^{\circ} \mathrm{S}, 140^{\circ}-80^{\circ} \mathrm{W}$, with data output as 5-day means. The model has 50 vertical levels of which 20 are within $1000 \mathrm{~m}$ of the surface; we note that this is less than the ideal and may lead to higher melt rates than a model with higher vertical resolution (Schodlok et al. 2016). Open boundary conditions are derived from a mean annual cycle of potential temperature and salinity from World Ocean Atlas 2009 (Locarnini et al. 2010; Antonov et al. 2010) and a mean annual cycle of currents derived from a circumpolar setup of MITgcm run at $0.25^{\circ}$ resolution (Assmann et al. 2013). Bathymetry and ice shelf thickness are extracted from RTOPO1.0.5 (Timmermann et al. 2010), which is a source of uncertainty in the simulation, especially for poorly mapped regions of the Amundsen Sea. The model is forced at the surface using 6-hourly NCEP Climate Forecast System Reanalysis (CFSR; Saha et al. 2010) data from 1979-2011 following a 10-yr spinup with perpetual 1979 conditions. All subsequent time-mean calculations use the full 1979-2011 time range. CFSR performed well in a recent evaluation (Jones et al. 2016) of various reanalysis products against in situ observations in the Amundsen Sea. Note that all reanalysis products performed better over the open ocean than over land or close to the coasts (Jones et al. 2016), so we expect substantial uncertainties relating to air-sea fluxes and wind stress near the coasts, which may hamper the simulation of regional processes such as observed by Webber et al. (2017).

\section{b. Calculation of heat transport, overturning, and CDW fluxes}

We calculate temperature transports through various sections (see Fig. 1) relative to the in situ freezing point of seawater following Kalén et al. (2016). For a given section, the total temperature transport is given by

$$
Q_{H}=\int_{x_{1}}^{x_{2}} \int_{-H}^{0} \rho C_{p} v\left(T-T_{f}\right) d x d z,
$$

where $x$ is horizontal distance $(\mathrm{m})$, and $x_{1}$ and $x_{2}$ define the horizontal limits of the section, $z$ is height and $H$ is 


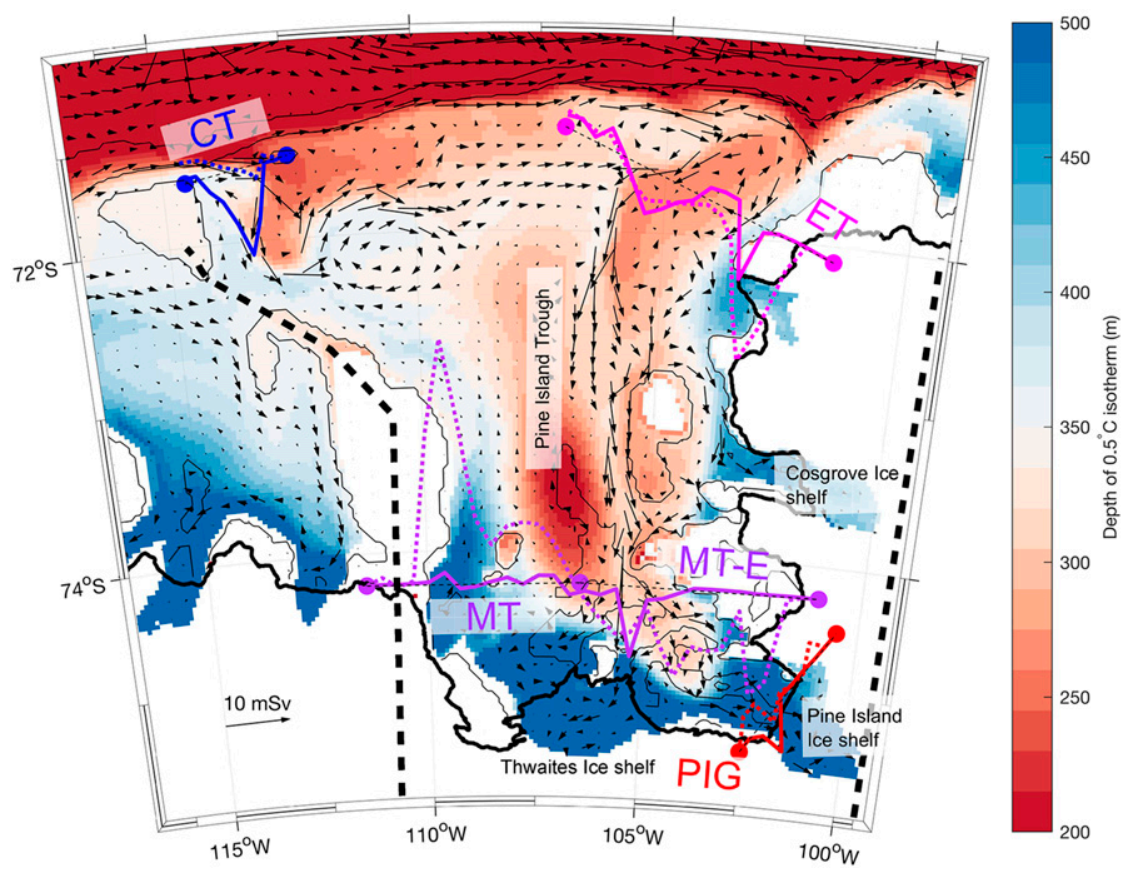

FIG. 1. Time-mean (1979-2011) $0.5^{\circ} \mathrm{C}$ isotherm depth ( $\mathrm{m}$; shaded; see color bar) and volume flux of water warmer than $0.5^{\circ} \mathrm{C}$ ( $\mathrm{mSv}$; vectors; see scale). The cross-trough sections are shown with colored dots at each end and a black dashed line. Flux of water warmer (colder) than $0.5^{\circ} \mathrm{C}$ through each section is plotted as solid (dashed) lines relative to the section. The sections are CT (blue; $71.6^{\circ}-71.48^{\circ} \mathrm{S}, 114.45^{\circ}-112.5^{\circ} \mathrm{W}$ ), ET (magenta; $71.35^{\circ}-72.1^{\circ} \mathrm{S}, 107^{\circ}-101.5^{\circ} \mathrm{W}$ ), MT (purple; $74.2^{\circ} \mathrm{S}, 111.4^{\circ}-102^{\circ} \mathrm{W}$ ), MTE (purple; $74.2^{\circ} \mathrm{S}, 106.5^{\circ}-102^{\circ} \mathrm{W}$ ), and PIG (red; $75.2^{\circ}-$ $74.4^{\circ} \mathrm{S}, 102.5^{\circ}-100.5^{\circ} \mathrm{W}$ ). The thick black line denotes the coastline or ice shelf calving front, while bathymetry is contoured as thin black lines at 500,1000, and $2000 \mathrm{~m}$. The approximate zonal limits of the overturning calculation are shown by the thick black dashed lines.

the local depth of the deepest model level (m), $\rho$ is in situ density $\left(\mathrm{kg} \mathrm{m}^{-3}\right), C_{p}$ is specific heat capacity of seawater $\left(\mathrm{J} \mathrm{kg}^{-1} \mathrm{~K}^{-1}\right), v$ is the velocity component normal to the section in the onshore direction $\left(\mathrm{m} \mathrm{s}^{-1}\right), T$ is the in situ temperature $\left({ }^{\circ} \mathrm{C}\right)$, and $T_{f}$ is the surface freezing point temperature. The $Q_{H}$ represents the heat available to melt ice (e.g., Walker et al. 2007). Note that throughout this manuscript we refer to this quantity as temperature transport, since it is not strictly appropriate to determine a heat transport (or heat flux) through a section with nonzero volume flux (e.g., Schauer and Beszczynska-Möller 2009).

Following Kalén et al. (2016), we split the velocity into barotropic (depth mean) and baroclinic (residual) components $\left(v_{\mathrm{BT}}\right.$ and $v_{\mathrm{BC}}$, respectively) and compute the barotropic and baroclinic temperature transports by substitution of $v_{\mathrm{BT}}$ and $v_{\mathrm{BC}}$ for $v$ in Eq. (1). We similarly compute the overturning and residual temperature transports by substituting the zonal mean and zonally varying velocity components for $v$ in Eq. (1). The temperature transport can be further decomposed by taking the time mean and time-varying components of temperature $\left(\bar{T}\right.$ and $\left.T^{\prime}\right)$ and velocity $\left(\bar{v}\right.$ and $\left.v^{\prime}\right)$ respectively, which are combined to produce time series of temperature transport due to the mean circulation $\bar{v} \bar{T}$, temperature variation only $v^{\prime} \bar{T}$, velocity variation only $\bar{v} T^{\prime}$, and covariance between velocity and temperature $v^{\prime} T^{\prime}$. Although only $\bar{v} \bar{T}$ and $v^{\prime} T^{\prime}$ can have a nonzero time mean, the temporal variability of the latter three terms can all contribute to the total temporal variability, and it is instructive to compare the magnitude of the variance of each and the correlation of each with the total temperature transport.

We calculate the overturning circulation in Pine Island Trough in both depth and density space. The overturning in depth space is intuitively easier to understand and is often used to present the global meridional overturning circulation (e.g., Rahmstorf et al. 2015). Horizontal variations in density can be such that the overturning in depth space is not equivalent to the overturning in density space. The overturning in density space is facilitated by the addition of buoyant glacial meltwater and is perhaps the most appropriate measure of the true overturning strength in this region. Here we present both since it is 
important to determine the differences between the two definitions for comparison with other depth-based overturning calculations.

We define the meridional overturning streamfunction in depth space as

$$
\psi_{z}(y, z, t)=\int_{-H}^{Z} \int_{x_{w}}^{x_{e}} v(x, y, z, t) d x d z,
$$

where $x_{w}$ and $x_{e}$ are the western and eastern boundaries (zonal limits shown by dashed lines in Fig. 1), respectively, at depth $Z$, and $v$ is the northward velocity. In potential density $\rho_{\theta}$ space, the meridional overturning streamfunction is calculated as follows:

$$
\psi_{\rho}\left(y, \rho_{\theta}, t\right)=\int_{\rho_{H}}^{\rho_{z}} \int_{x_{w}}^{x_{e}} v\left(x, y, \rho_{\theta}, t\right) d x d \rho_{\theta} \frac{d z}{d \rho_{\theta}},
$$

with $d \rho_{\theta}\left(d Z / d \rho_{\theta}\right)$ giving the thickness of each density layer when discretized. The potential density axis is chosen such that the thickness of each layer is approximately equal to the model depth spacing within the Pine Island Trough region. The overturning temperature transport is calculated in density space as

$$
Q_{\psi}=\int_{\rho_{H}}^{\rho_{0}} \int_{x_{w}}^{x_{e}}\left\langle\rho C_{p}\left(T-T_{f}\right)\right\rangle v\left(x, y, \rho_{\theta} t\right) d x d \rho_{\theta} \frac{d z}{d \rho_{\theta}},
$$

where \langle\rangle denotes a zonal average for a given density level. This zonal average removes the covarying velocity and temperature signals at each density level, which contributes instead to the temperature transport induced by the isopycnal circulation.

We compute the depth of the CDW layer and the total flux of CDW at each grid point. For computational efficiency we define the upper boundary of the CDW layer $\left(z_{\mathrm{CDW}}\right)$ to be the deepest layer at which the potential temperature is less than $0.5^{\circ} \mathrm{C}$. The CDW flux is then calculated as the volume flux of water between the deepest model layer and the top of the CDW layer. The flux of CDW through the sections defined above is given by the volume flux onshore through the section integrated from the seafloor to $z_{\mathrm{CDW}}$.

\section{c. Model validation}

Since our present study is concerned with the flow of CDW along Pine Island Trough, we compare the model temperature and salinity with observations along Pine Island Trough in 2009 (Jacobs et al. 2011), from the shelf break at $103^{\circ} \mathrm{W}$ to the front of Pine Island ice shelf (Fig. 2e). For the comparison, we interpolate the model data to the time and location of the CTD casts used for the construction of this section. The model reproduces the temperature and salinity structure along Pine Island
Trough, with the core of warmest and saltiest CDW located offshore and the main thermocline located around $300-\mathrm{m}$ depth, deepening to around $500 \mathrm{~m}$ at the ice shelf front (Figs. 2a,b). However, the model CDW is around $0.4^{\circ} \mathrm{C}$ too warm along much of the section, and the thermocline is around $100 \mathrm{~m}$ too shallow at the shelf break. The model does not capture the observed doming of the thermocline within the gyre in Pine Island Bay. The salinity of the CDW is also slightly fresher than observed while the Winter Water (WW) layer is too salty (Figs. 2c,d), which will contribute to a reduced vertical density gradient. We note that these biases in CDW and WW properties, as well as in the depth of the thermocline, are common to many models (Nakayama et al. 2017). The distribution of thermocline depth and circulation of warm water onto and around the continental shelf (Fig. 1) are broadly consistent with previous modeling studies (Schodlok et al. 2012; Nakayama et al. 2014b; St-Laurent et al. 2015) and with the available observational data (Nakayama et al. 2013; Heywood et al. 2016; Mallett et al. 2018).

The poor performance close to the coasts of the atmospheric reanalysis product used to force the model may explain why the model does not capture the gyre in front of the Pine Island ice shelf (Thurnherr et al. 2014). The lack of a gyre will influence how heat is exchanged with the ice shelf and how this heat exchange varies over time. The gyre traps heat and salt in the center of Pine Island Bay and upwells the thermocline in the center of the Bay. Observations from seal data (Heywood et al. 2016; Mallett et al. 2018) and moorings (Webber et al. 2017) show that this gyre feature is not permanent but instead varies in position and direction; the mechanisms behind this variability are not yet clear. The lack of this gyre feature suggests that the structure of the flow through the Pine Island Glacier section (Fig. 1) may be poorly captured. However, the present configuration of the model has been shown to reproduce the broad features of the observed on-shelf flow of CDW at the continental shelf break (Assmann et al. 2013) and further onshore (Kalén et al. 2016), with discrepancies most likely due to errors in the bathymetry. We are therefore more confident in the structure of the flow through the shelf edge and Pine Island Trough sections than for the Pine Island Glacier section where discrepancies exist.

It is also important to verify that the model is able to simulate realistic interannual variability, especially on the decadal time scales investigated in this study, although given the sparse observations it is hard to test this fully. Figure 12 of Assmann et al. (2013) shows that the model sea ice extent agrees very well $(r=0.86)$ with satellite observations over the Amundsen Sea, suggesting that the near-surface interannual variability is well 

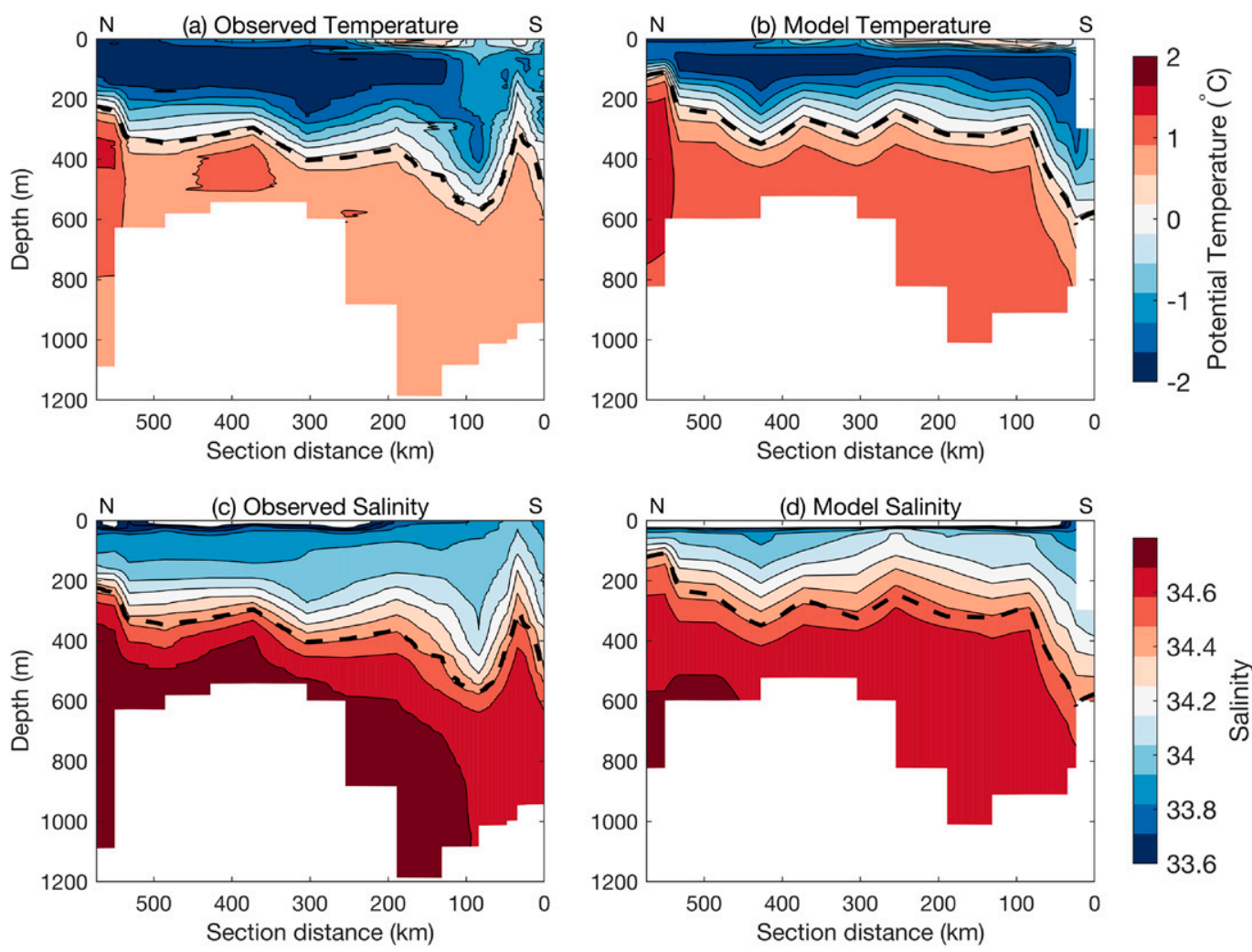

(e) Location of observations
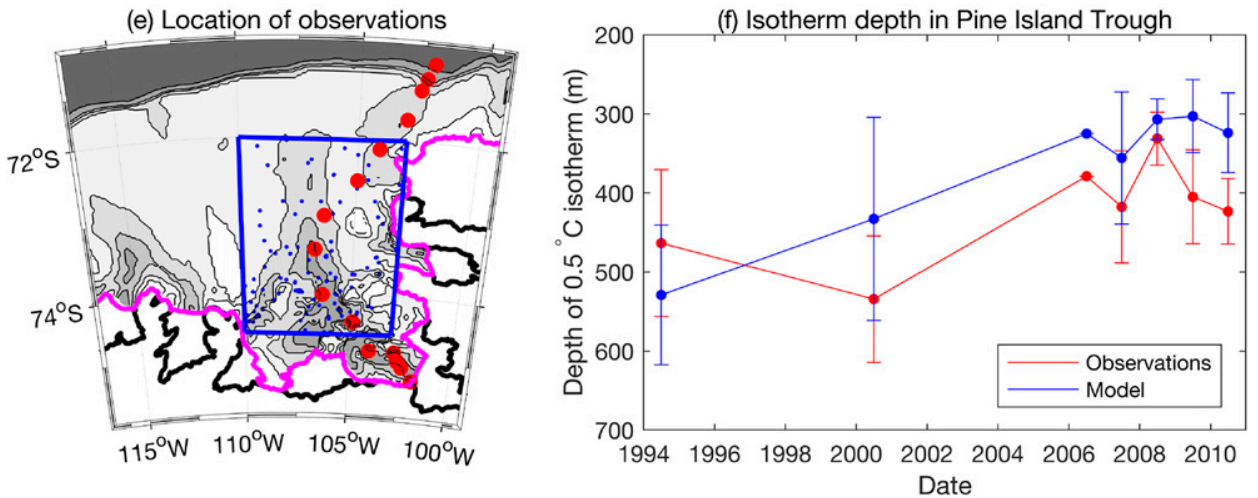

FIG. 2. (top) Potential temperature and (middle) salinity along Pine Island Trough from (a),(c) CTD observations [red circles in (e); Jacobs et al. 2011] and (b),(d) model data interpolated to the time and location of the observations; the depth of the CDW layer is shown as the thick dashed line. (e) Red dots: location of observations used in (a)-(d); blue dots: location of observations used in (f). (f) Time series of $0.5^{\circ} \mathrm{C}$ isotherm depth from available ship observations [red; see Dutrieux et al. (2014) for details] and model data (blue) interpolated to the time and location of the available ship observations within Pine Island Trough [blue box in (e)]; error bars show the standard deviation of the data within this region.

simulated. Using all available ship observations [see Dutrieux et al. (2014) for details], we compare the thermocline variability in Pine Island Trough from observations against the model data interpolated to the time and location of the observations. To ensure good temporal coverage we take the average within the comparatively well-sampled region from $103^{\circ}-110^{\circ} \mathrm{W}$, $72^{\circ}-74.5^{\circ} \mathrm{S}$ (Fig. 2e). The model thermocline is typically
$50-100 \mathrm{~m}$ shallower than suggested by observations; nevertheless, the shoaling trend from 1994 to 2009 is well represented, and the model captures some of the subsequent decrease from 2009 to 2011 (Fig. 2f). Since the model open boundary conditions are derived from climatology, we do not capture changes in the farfield ocean that may influence the conditions in the Amundsen Sea. 
To evaluate the realism of the modeled transport of water onto the continental shelf, we compare the flux of temperature and CDW through the central trough during March 2003 with the observations obtained during that month by Walker et al. (2007). To facilitate comparison, we interpolate the model temperature and salinity to the location and time of the CTD stations used for the cross-trough section by Walker et al. (2007). We then interpolate the model velocities to the midpoint of each station pair and calculate the corresponding orthogonal onshore velocity. At this time, the model thermocline is again $50-100 \mathrm{~m}$ too shallow (not shown), such that the temperature between 300- and 450-m depth is up to $1^{\circ} \mathrm{C}$ too warm, while the onshore velocity is too strong. As a result, the modeled temperature transport (CDW flux) of $4.94 \mathrm{TW}(332 \mathrm{mSv})$ exceeds the observed values of $2.8 \pm 0.68 \mathrm{TW}(234 \pm 62 \mathrm{mSv})$.

Consistent with the model warm bias, the mean model melt rate for Pine Island Glacier $\left(107.6 \mathrm{~km}^{3} \mathrm{yr}^{-1}\right)$ is at the high end of the observed range (34.7-107.3 $\mathrm{km}^{3} \mathrm{yr}^{-1}$; Dutrieux et al. 2014). It is not clear where the model warm bias originates. The boundary conditions are derived from a combination of observed and model climatologies and may contain biases. Alternatively, the bias may be related to the relatively coarse resolution of the thermocline and its interaction with the ice shelves or due to biases in the surface forcing.

Overall, we conclude that the model representation of CDW flow onto the shelf and around Pine Island Trough is broadly realistic, but we interpret the flow pattern close to the ice shelves with caution. The shape of the cavity is known to influence the melt rate (Schodlok et al. 2012), and in reality this will change over time and thus may influence the circulation (Jourdain et al. 2017); since the model ice shelf cavities do not change shape, we do not expect the model to perfectly reproduce past changes. Furthermore, the climatological boundary conditions do not account for far-field changes, and there are significant uncertainties in all reanalysis products in the region, which can cause significant differences in model simulations forced by different products (Kimura et al. 2017). However, such models are useful as tools to investigate the oceanic processes and their variability in response to a given atmospheric forcing.

\section{Results}

\section{a. Temperature and CDW transport onto and around the continental shelf}

CDW flows onto the shelf at two key locations, the central (CT; blue in Fig. 1) and the eastern (ET; magenta in Fig. 1) troughs, with the influx in the latter split into two cores. CDW continues southward through the eastern midtrough (MTE) section toward Pine Island and Thwaites ice shelves, similar to the flow pattern suggested by Schodlok et al. (2012), Assmann et al. (2013), and Nakayama et al. (2013). The imbalance in the flux of CDW through the whole midtrough (MT) section (purple in Fig. 1) suggests that most of the CDW flowing south is converted to cooler water masses by the addition of meltwater before returning north in the western half of the section.

The time-mean cross-section velocity and temperature for each section (Fig. 3) demonstrates that the velocity structure is very different between the central and eastern troughs, with a deep inflow through CT but a more vertically uniform inflow through ET. At MT, the strongest circulation is in the cold near-surface layers, but there is a substantial inflow of CDW around $105^{\circ} \mathrm{W}$ that is not balanced by an outflow within the CDW layer (i.e., below the $0.5^{\circ} \mathrm{C}$ isotherm). For the Pine Island Glacier (PIG) section, there is a combination of horizontal and vertical circulation, with the strong inflow between 600 and $1000 \mathrm{~m}$ balanced primarily by the return flow between the surface and $400 \mathrm{~m}$ toward the western end of the section. However, we note that while the model simulates the inflow and outflow into Pine Island Bay, the circulation does not close in a gyre as observed farther north (Thurnherr et al. 2014) and thus may underestimate the horizontal circulation through this section.

The structure of temperature and velocity at CT agrees well with observations in 2003 (Walker et al. $2007,2013)$, when a deep inflow was observed around $113.5^{\circ} \mathrm{W}$ coincident with the warmest temperatures, while the thermocline sloped slightly from east to west. There are no published observations that correspond exactly to the ET section; however, preliminary analysis of geostrophic velocities across a zonal section in a similar location does show an equivalent barotropic inflow at $103^{\circ} \mathrm{W}$ in agreement with our model results (M. Azaneu 2018, personal communication). There are also no published observations corresponding to the MT section, but temperature observations from seal tags at $73^{\circ} \mathrm{S}$ (Mallett et al. 2018) suggest that the depth of the $0.5^{\circ} \mathrm{C}$ isotherm is shallowest $(350 \mathrm{~m})$ around $105.5^{\circ} \mathrm{W}$ and deepens both westward and eastward, with the maximum observed depth of $500 \mathrm{~m}$ at $107^{\circ} \mathrm{W}$. The thermocline structure in the model exhibits a minimum depth (again $350 \mathrm{~m}$ ) of the $0.5^{\circ} \mathrm{C}$ isotherm at $106.5^{\circ} \mathrm{W}$, slightly farther west than the observations but still comparable given the latitudinal offset. The observed circulation at the PIG section is highly variable (Dutrieux et al. 2014, their Figs. S4 and S5), but the $0.5^{\circ} \mathrm{C}$ isotherm is typically around $500 \mathrm{~m}$, with a combination of vertical 
(a) CT

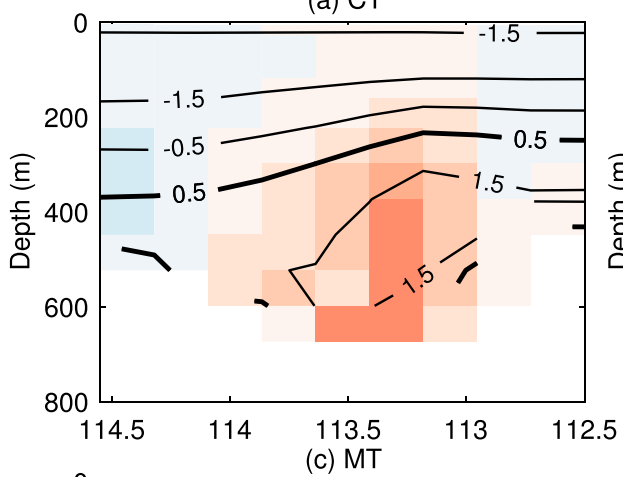

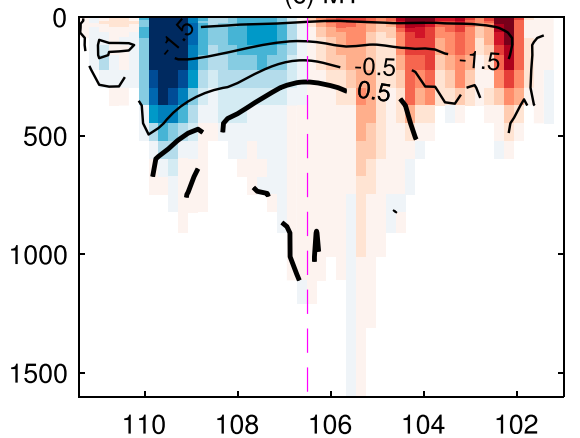

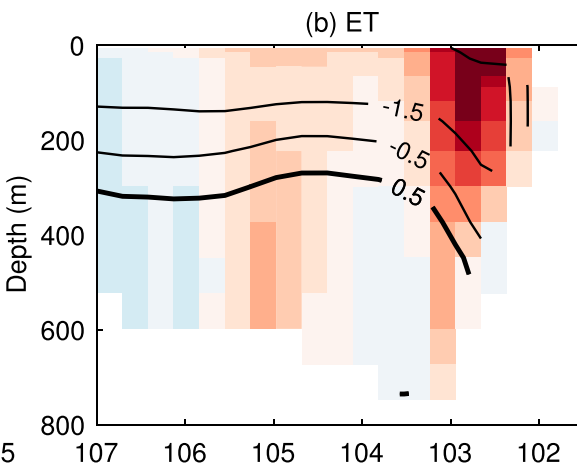

(d) PIG

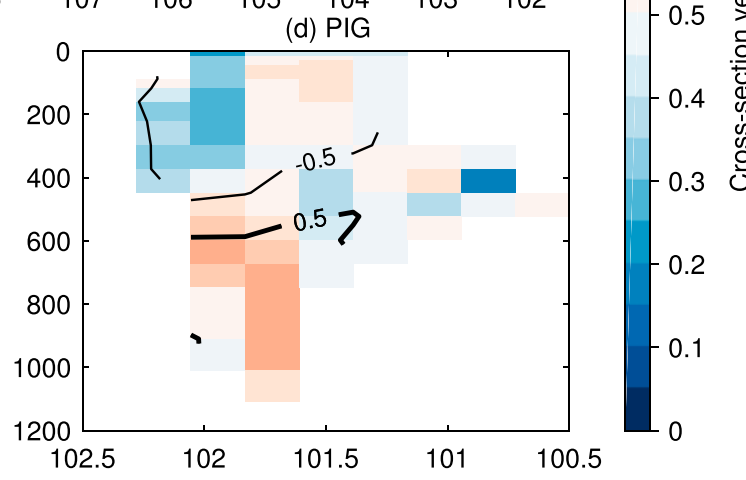

FIG. 3. Time mean of cross-section velocity ( $\mathrm{m} \mathrm{s}^{-1}$; shaded; positive southward) and temperature (contours; $0.5^{\circ} \mathrm{C}$ in bold) for sections (a) CT, (b) ET, (c) MT, and (d) PIG. The dashed magenta line in (c) shows the western boundary of the MTE section.

and horizontal circulation comprising full-depth inflow at the northwestern end and a shallower outflow at the southeastern end (Dutrieux et al. 2014; Jacobs et al. 2011; Nakayama et al. 2013). Our PIG section is broadly consistent with these observations, although the deep inflow at the northwestern end is missing in our model.

To determine how much of the heat entering Pine Island Bay is used to melt the ice shelves, we calculate the heat flux associated with the ice shelf freshwater flux as

$$
Q_{\mathrm{FW}}=\rho_{\mathrm{FW}} L_{f} V_{\mathrm{FW}},
$$

where $\rho_{\mathrm{FW}}$ is the density of freshwater $\left(1000 \mathrm{~kg} \mathrm{~m}^{-3}\right), L_{f}$ is the latent heat of fusion $\left(3.33 \times 10^{5} \mathrm{~J} \mathrm{~kg}^{-1}\right.$; valid for freshwater at $500 \mathrm{dbar}$, neglecting the small variability in this quantity depending on ice shelf thickness), and $V_{\mathrm{FW}}$ is the area integrated melt rate $\left(\mathrm{m}^{3} \mathrm{~s}^{-1}\right)$ for Pine Island and Thwaites ice shelves. Approximately two-thirds of the net ocean temperature transport $(3.3 \pm 2.1 \mathrm{TW})$ through MT is used to melt the ice shelves $(2.1 \pm 0.37 \mathrm{TW})$, while the remainder is accounted for by surface fluxes. The fraction of heat lost to the atmosphere would be larger if the budget of heat flowing onto the continental shelf was considered, owing to the larger area available for surface heat loss. Note that our results are not comparable with the thermal efficiency calculated by Jourdain et al. (2017), nor the melting efficiency calculated by Bindschadler et al. (2011), since these quantities relate to the quantity of heat input (not net heat flux, which in their case is zero) that is used to melt the ice. If we estimate the heat input as the temperature transport by the southward flow through the MT section (10.6 TW), we arrive at a melting efficiency of $18.5 \%$ for Pine Island and Thwaites ice shelves, consistent with the 19\% calculated by Jourdain et al. (2017) for Pine Island ice shelf.

\section{b. Meridional overturning circulation in Pine Island Trough}

The conversion of CDW into cooler but lighter meltwater generates a meridional overturning circulation in Pine Island Trough facilitated by ice shelf melt (Fig. 4). In depth space (Fig. 4a) the time-mean meridional overturning shows a negative (clockwise looking west) cell centered on approximately 500-m depth, extending along the entire trough. The strongest meridional overturning of approximately $0.3-\mathrm{Sv}$ amplitude occurs close to $75^{\circ} \mathrm{S}$ as the flow enters the Pine Island and Thwaites cavities, and the cell deepens as it extends toward the grounding lines of these glaciers at around $800 \mathrm{~m}, 75.25^{\circ} \mathrm{S}$ (Fig. 4a). The maximum overturning seen here is comparable with an observational estimate of $0.25 \mathrm{~Sv}$ of overturning within Pine Island cavity (Jacobs et al. 2011; Thurnherr et al. 2014). 


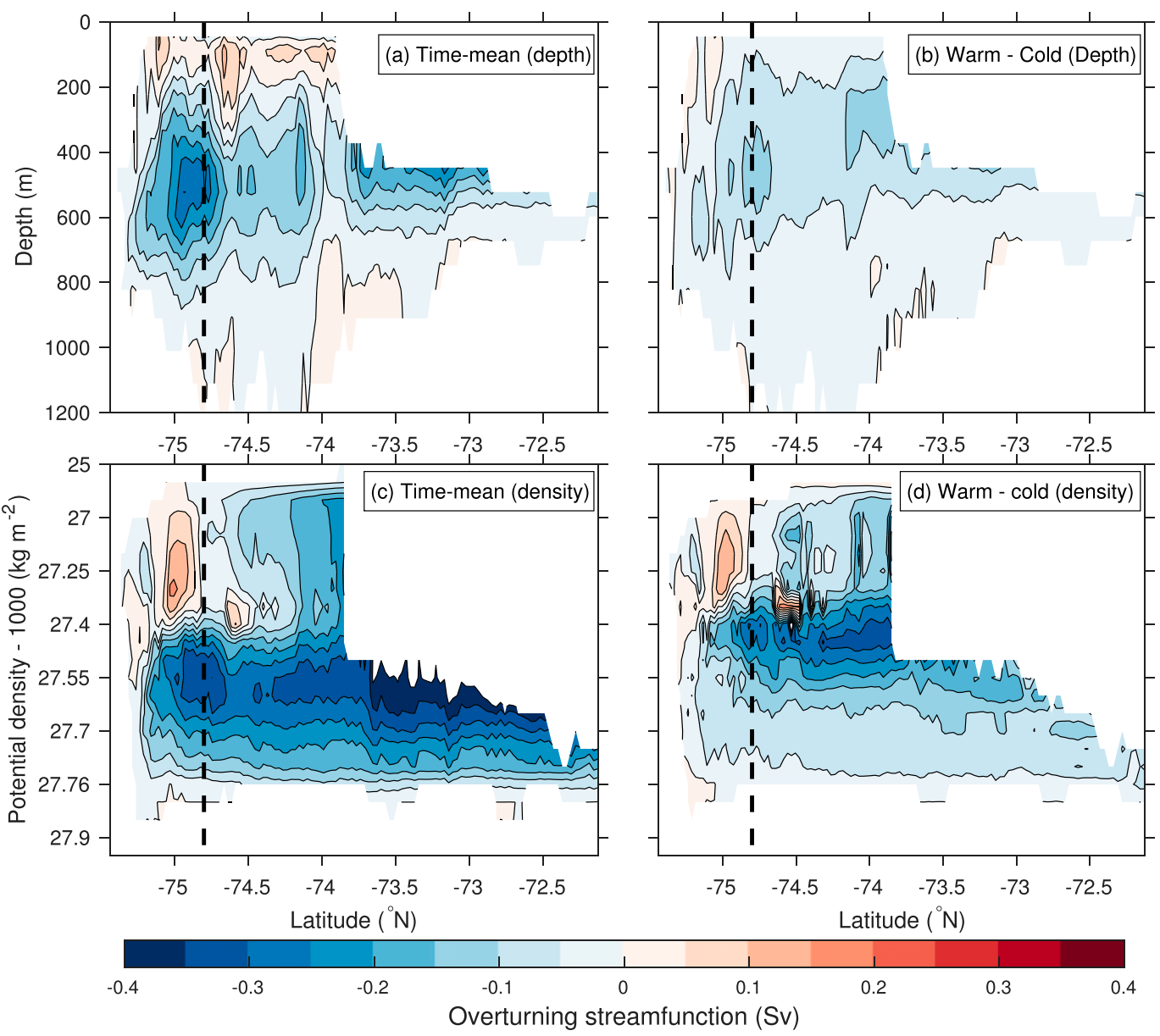

FIG. 4. Overturning streamfunction (Sv; shaded; see legend) against latitude and (a),(b) depth (m) and (c),(d) potential density $\left(\mathrm{kg} \mathrm{m}^{-3}\right)$; note the density axis spacing is not even. Time-mean overturning is plotted in (a) and (c); streamfunction difference between the warmest five and coldest five years (Fig. 5f) is plotted in (b) and (d). The approximate northernmost extent of the Pine Island and Thwaites cavities $\left(74.8^{\circ} \mathrm{S}\right)$ is shown by the vertical dashed lines.

If the inflow of warm salty water and the outflow of cooler fresher water are not well separated in depth, the overturning in density space may be more representative of the true overturning circulation. The meridional overturning cell in density space is centered on $1027.55 \mathrm{~kg} \mathrm{~m}^{-3}$, consistent with the $500-\mathrm{m}$ depth of the overturning cell in depth space (Fig. 4c). The meridional overturning streamfunction in density is flatter than in depth space, since fluctuations in isopycnal depth along the trough are removed. In addition, the density-space overturning cell is more latitudinally consistent in strength, indicating that the longitudinal change in isopycnal depth at certain latitudes is such that inflow and outflow overlap in depth space but not density space. The overturning circulation in density space is slightly stronger than in depth space, peaking at an amplitude of $0.38 \mathrm{~Sv}$.

\section{c. Temporal variability of temperature transports}

We now examine the temporal variability of temperature transport through the various sections around the Amundsen Sea. We note that the temperature transport through open sections with nonzero net transport is highly dependent on the width of the section and the choice of end points (e.g., Schauer and Beszczynska-Möller 2009). Here we choose our shelf-edge sections to cover the main inflows of CDW onto the continental shelf, as the temperature transport through such sections has previously been compared to the heat required to melt the ice shelves (e.g., Walker et al. 2007). However, the temperature transport through the closed MT and PIG sections is a more robust and less ambiguous approximation of the total heat transport.

There is substantial decadal variability in the annualmean time series of temperature transport that is common 
between all sections (Fig. 5). The transport of temperature is well correlated $(r=0.80)$ between the two shelfedge sections. The total temperature transport for all sections decreases from a maximum in the 1980s to a minimum in the late 1990s followed by larger temperature transports between 2005 and 2010. This covariability suggests that the temperature transports onto the continental shelf influence those at the ice shelf front, at least over multiannual time scales. On short time scales local surface heat loss within polynyas combined with changes in wind stress and ice cover can drive variability close to Pine Island Glacier (St-Laurent et al. 2015; Webber et al. 2017), which may partly explain differences between individual years.

The changes that contribute to the decadal temperature transport variability are shown by composites of cross-section velocity and temperature anomalies for the five warmest and five coldest years as defined by the melt rate of Pine Island and Thwaites ice shelves (Fig. 6; see Fig. $5 \mathrm{f}$ for years). We note that the response of ice shelves to transient ocean forcing might be expected to create a lag between the changes in ocean conditions and the changes in melt rate (Holland 2017), but the time lag is small compared with the decadal time scales that dominate the variability, and there is good agreement between the time series of melt rate and heat transports across the continental shelf (Fig. 5). In general, the velocity anomalies for warm years have a similar structure to (and the same sign as) the mean circulation, indicating that the circulation is stronger in warm years. Meanwhile, circulation anomalies for cold years have the opposite sign to the mean circulation, indicating that the circulation weakens in cold years. The thermocline deepens in cold years, with the largest temperature anomalies close to the thermocline depth where the vertical temperature gradient is largest. The thermocline depth changes are larger at the MT and PIG sections than at the shelf-edge sections. At the CT section (Figs. 6a,b), the changes are largely baroclinic, with opposite velocity anomalies above and below the thermocline; nevertheless, these changes project onto the depth-mean volume transport and thus the barotropic temperature transport (see below). For the ET section (Figs. 6c,d), the deep inflows at $103^{\circ}$ and $105^{\circ} \mathrm{W}$ strengthen in warm years while the surface inflow weakens; in cold years the reduction in inflow is apparent throughout the water column. At MT (Figs. 6e,f), the largest velocity anomalies are in the near-surface layers; the outflow near $109^{\circ} \mathrm{W}$ strengthens (weakens) in warm (cold) years, while the inflow from $102^{\circ}$ to $107^{\circ} \mathrm{W}$ generally does the same, but with opposite anomalies near $104^{\circ} \mathrm{W}$ indicating differences in the location of the strongest inflows. Meanwhile, the main inflow of CDW at MT, at $105^{\circ}-106^{\circ} \mathrm{W}$, strengthens in warm years and weakens in cold years, with changes in CDW transport amplified by the changes in the thermocline depth. At the PIG section (Figs. 6g,h), the largest anomalies are a dipole pattern between $101.5^{\circ}$ and $102^{\circ} \mathrm{W}$ below $600 \mathrm{~m}$, suggesting a change in the structure of the inflow, but overall the total deep inflow strengthens (weakens) in warm (cold) years.

The velocity can be decomposed into a depth-mean (barotropic) and depth-varying (baroclinic) component (see section 2b). For all the open sections where there is strong onshore flow, the barotropic temperature transport dominates (Fig. 5). At CT, the barotropic (baroclinic) temperature transport accounts for $74 \%(26 \%)$ of the total (4.58 TW). At ET and MTE, the total temperature transports (7.70 and $10.07 \mathrm{TW}$, respectively) are again largely barotropic. At these troughs, the baroclinic temperature transports are again weak, but offshore ( $-27 \%$ and $-33 \%$ of the total, respectively). However, for the closed sections farther south, the southward barotropic temperature transport is compensated by a similar northward barotropic temperature transport, and the net barotropic heat transport is small. As a result, the total temperature transport for the MT and PIG sections (3.30 and 1.17 TW, respectively) is largely baroclinic, with the baroclinic temperature transport accounting for $84 \%$ and $140 \%$ of the total temperature transport, respectively (Fig. 5). Furthermore, the baroclinic temperature transport at MT is well correlated with the total temperature transport at PIG $(r=0.89)$ and at CT $(r=0.69)$ and ET $(r=0.84)$, while the barotropic temperature transport at MT is anticorrelated with the total temperature transport at these sections $(r=-0.60,-0.35$, and -0.48 , respectively).

Since temperature transport variability can be accounted for by changes in both temperature and velocity, we decompose the temperature transport variability into the components associated with fluctuations in temperature $\bar{v} T^{\prime}$, those associated with fluctuations in velocity $v^{\prime} \bar{T}$, and those associated with covariance between temperature and velocity $v^{\prime} T^{\prime}$. This analysis (Fig. 7) shows that fluctuations in velocity contribute most to the decadal variability, since the $v^{\prime} \bar{T}$ term agrees better in magnitude and temporal variability with the total temperature transport variability than either of the other terms at each section (in agreement with observations at the shelf break; Assmann et al. 2013). At the CT and PIG sections (Figs. 7b,d), it is only the $v^{\prime} \bar{T}$ term that exhibits substantial variability, consistent with the largest changes at these troughs being the deep velocity (Fig. 6). At the ET section (Fig. 7a), both $v^{\prime} \bar{T}$ and $\bar{v} T^{\prime}$ exhibit substantial variability that is correlated $(r=0.90$ and $r=0.80$, respectively) with the interannual variability of the total 
(a) Central trough (CT)

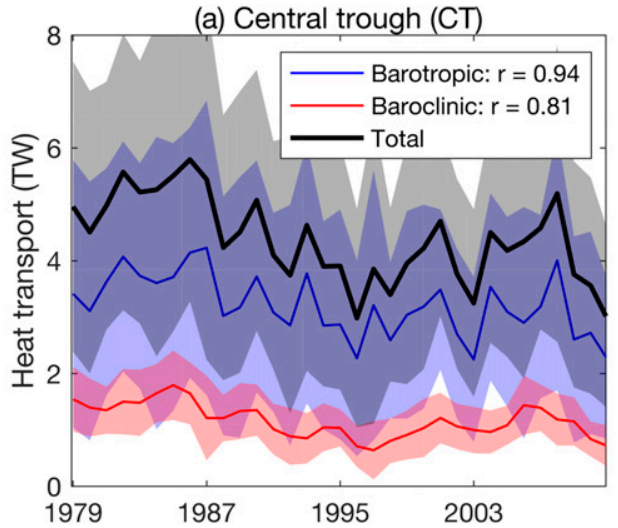

(c) Mid Trough East (MTE)

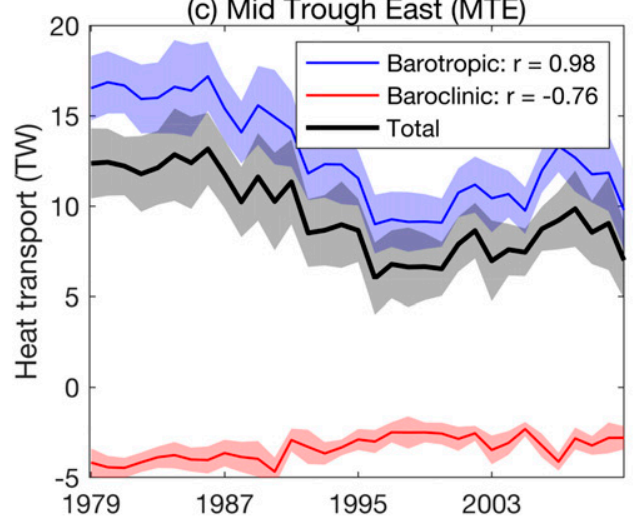

(e) Pine Island Glacier (PIG)

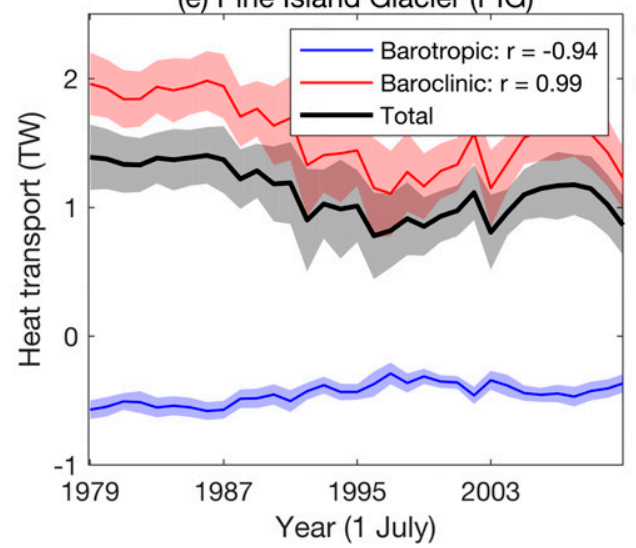

(b) Eastern trough (ET)

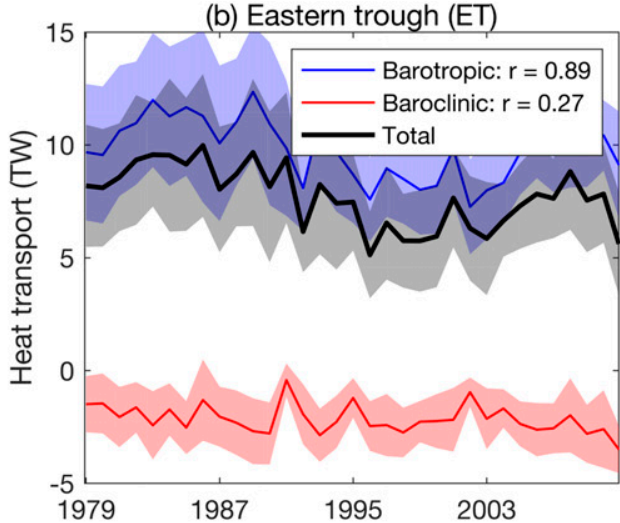

(d) Mid Trough (MT)

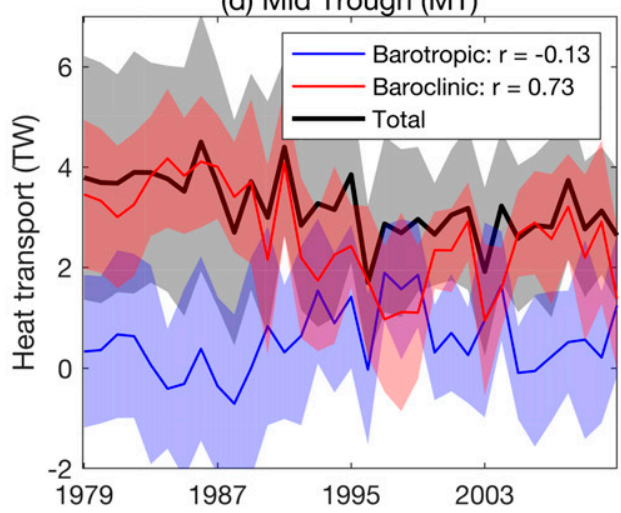

FIG. 5. Annual mean (line) and annual standard deviation (shading) of barotropic (blue), baroclinic (red), and total (black) temperature transport (TW; positive onshore or toward ice shelves) through sections (a) CT, (b) ET, (c) MTE, (d) MT, and (e) PIG. See Fig. 1 for section locations. The correlation coefficient between the total and the baroclinic and barotropic temperature transports, respectively, is given in the legends for each panel. Note difference in vertical axis scale between panels. (f) Annual mean (line) and annual standard deviation (shading) of melt rate of PIG and Thwaites combined (blue) and peak overturning streamfunction (red). The years used for the warm and cold composites are shown by black and green triangles, respectively, on the melt rate time series in (f). 

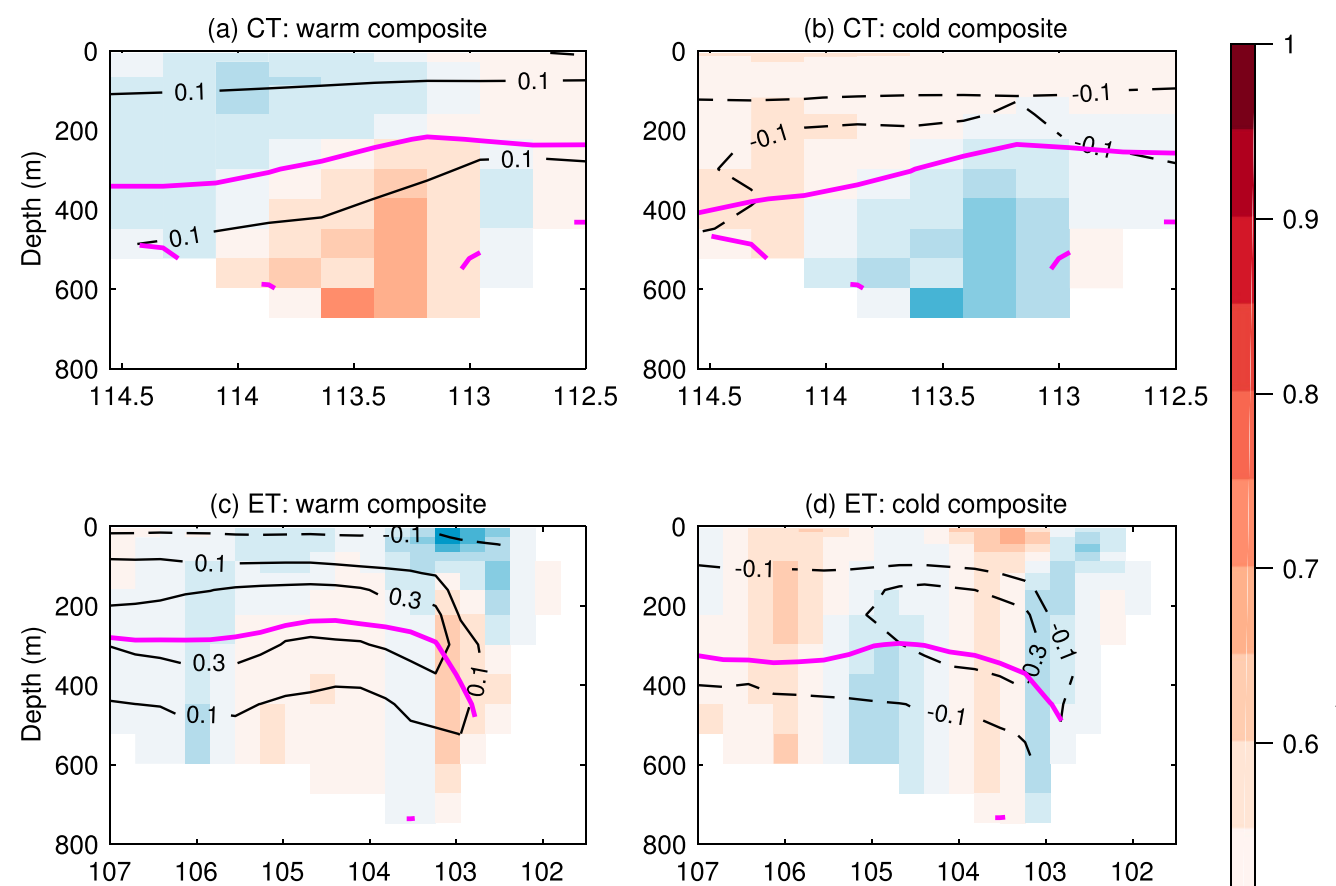

(e) MT: warm composite
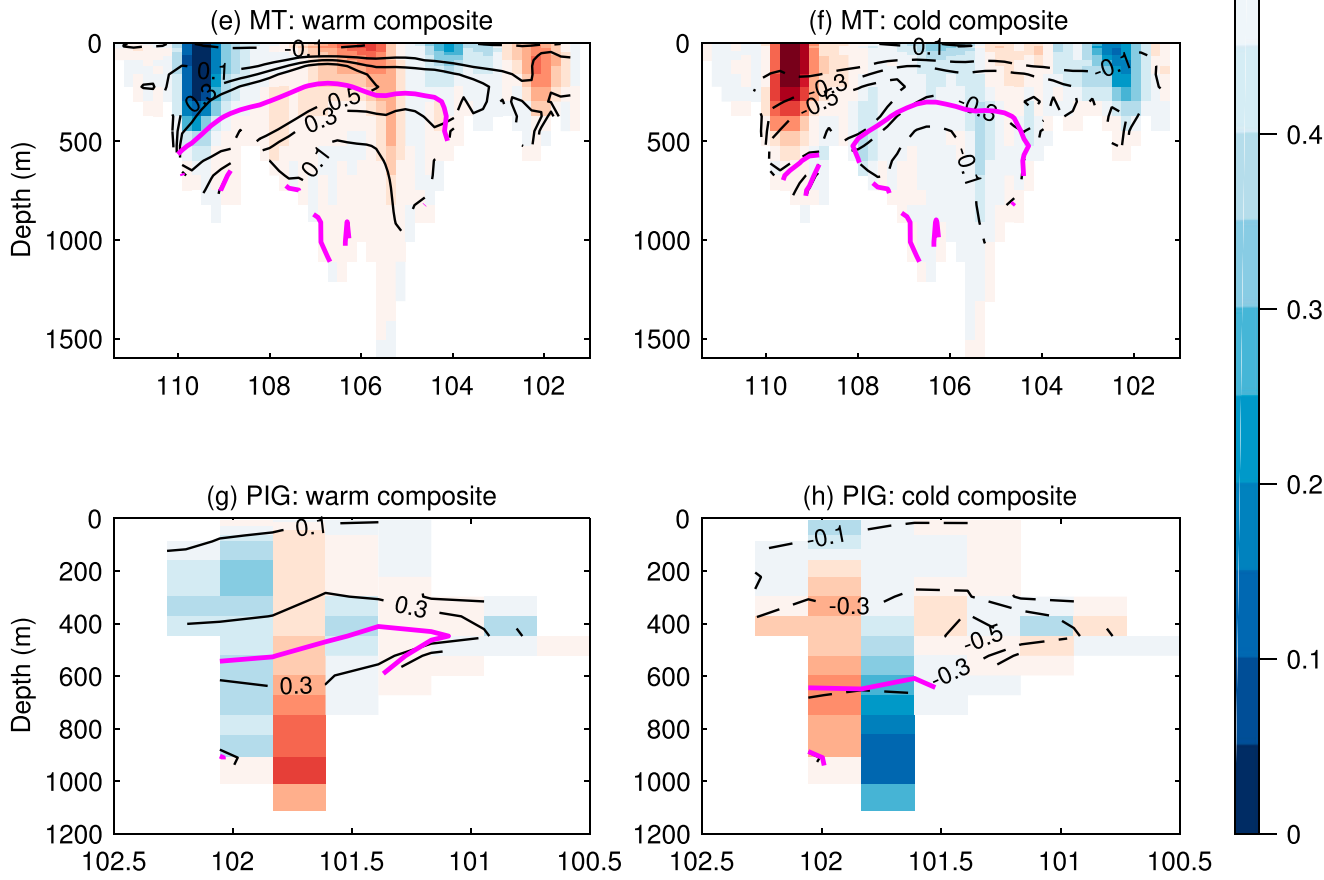

FIG. 6. Composites of cross-section velocity anomalies $\left(\mathrm{m} \mathrm{s}^{-1}\right.$; shaded; positive southward) and temperature anomalies (contours; $0.5^{\circ} \mathrm{C}$ contour in bold magenta) for (left) the five coldest years and (right) the five warmest years, as defined by the melt rate of PIG and Thwaites (Fig. 5f), relative to the 1979-2011 time mean. (a),(b) CT, (c),(d) ET, (e),(f) MT, (g),(h) PIG.

temperature transport. Meanwhile, at the MT section (Fig. 7c), both terms vary significantly, but the $v^{\prime} \bar{T}$ term is more strongly correlated with the total variability $(r=$ 0.73 , compared with $r=0.14$ for $\left.\bar{v} T^{\prime}\right)$, as well as the melt rate of the ice shelves $(r=0.86$, compared with $r=-0.45$ for $\bar{v} T^{\prime}$ ). In cold years, the outflow cools more than the inflow at MT (Figs. 6e,f), which may explain the increase in $\bar{v} T^{\prime}$ during the cooler periods. 
(a) ET: $\bar{V} \bar{T}=6.8874 \mathrm{TW}$

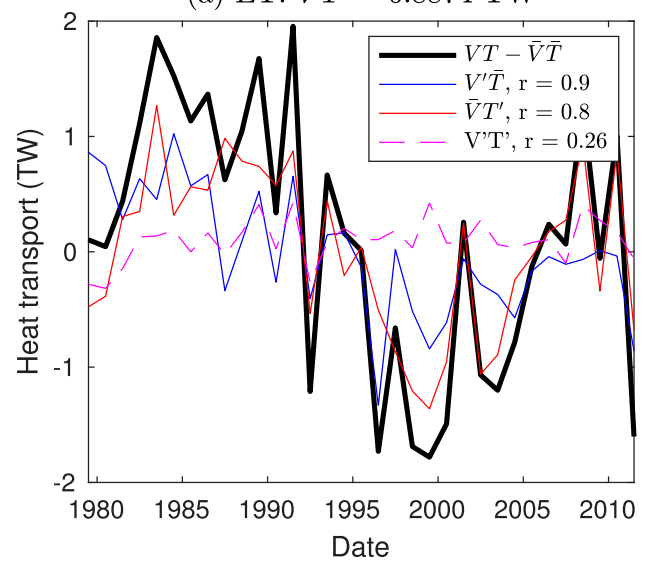

(c) MT: $\bar{V} \bar{T}=3.3144 \mathrm{TW}$

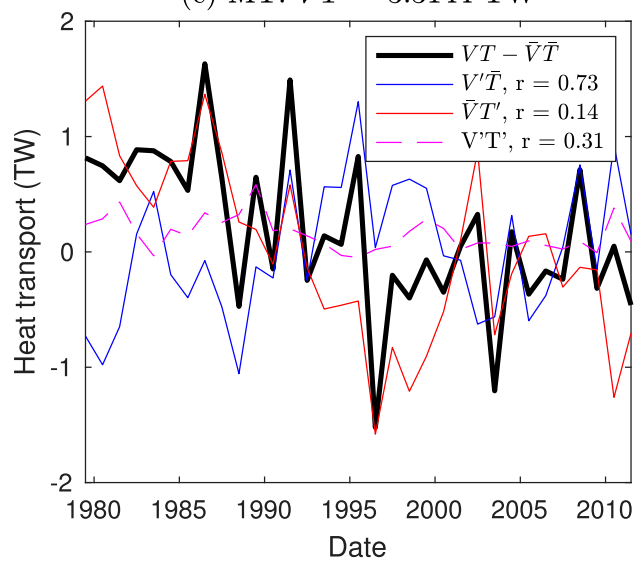

(b) $\mathrm{CT}: \bar{V} \bar{T}=5.3804 \mathrm{TW}$

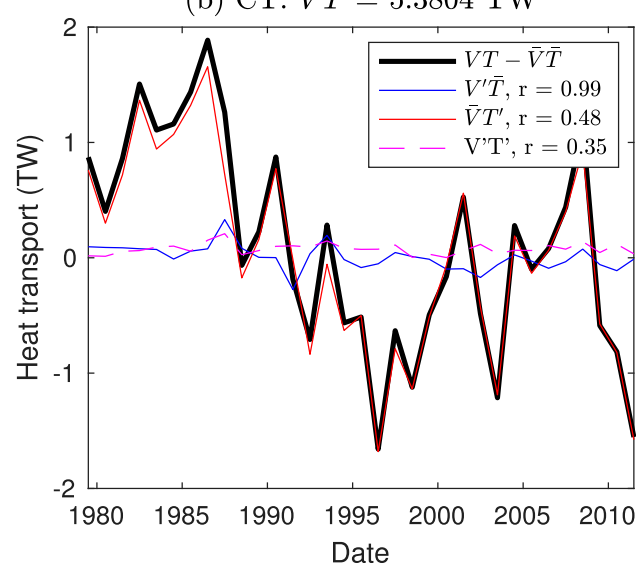

(d) PIG: $\bar{V} \bar{T}=1.7346 \mathrm{TW}$

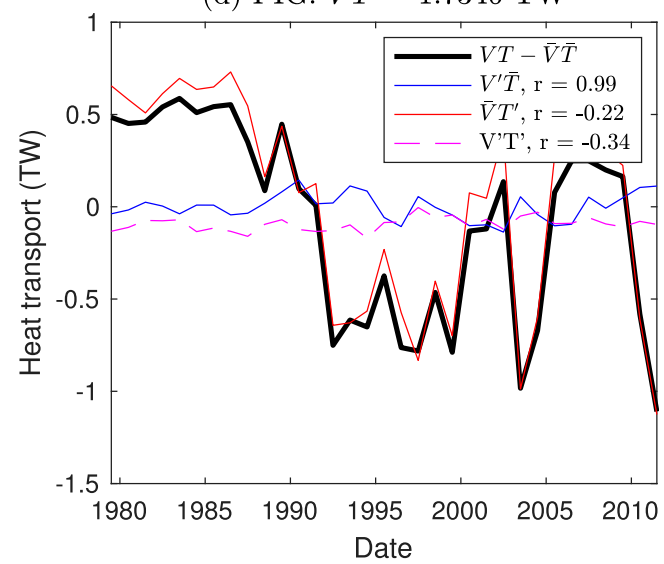

FIG. 7. Annual mean of temperature transport components: total minus time mean $(v T-\bar{v} \bar{T})$ (black lines); $v^{\prime} \bar{T}$ (red lines); $\bar{v} T^{\prime}$ (blue lines); $v^{\prime} T^{\prime}$ (magenta dashed lines) for the (a) ET, (b) CT, (c) MT, and (d) PIG. The value of $\bar{v} \bar{T}$ is subtracted from the total to facilitate comparison with the remaining terms and is given in the title of each panel. The correlation coefficient between $v T$ and each component, respectively, is given in the legend for each panel.

The spatial patterns of changes from warm to cold periods are shown by composite anomalies of the $0.5^{\circ} \mathrm{C}$ isotherm depth and CDW flux for the five warmest and five coldest years (Fig. 8). The $0.5^{\circ} \mathrm{C}$ isotherm shoals (deepens) in warm (cold) years by about $50 \mathrm{~m}$ across much of the continental shelf and by more than $100 \mathrm{~m}$ close to Pine Island and Thwaites ice shelves and on the western side of Pine Island Trough. These anomalies are smaller than the mean model bias (Fig. 2) but nevertheless imply substantial heat content changes. For comparison, an observed 250-m deepening of the thermocline in Pine Island Bay reduced the heat available to melt the ice shelf from 3.3 to $1.2 \mathrm{GJ}$ (Webber et al. 2017), coincident with a reduction in the flow speed of the ice shelf (Christianson et al. 2016). We expect that changes in thermocline depth and hence heat content close to and within the ice shelf cavity will lead to fluctuations in basal melt rate. The strength of the circulation within the cavity is also crucial (e.g., Jacobs et al. 2011; Jourdain et al. 2017), but this circulation will also increase with increasing melt rate (section $3 b$ ). The standard deviation of these composites (Figs. 8c,d) reveals considerable variability in the amplitude of the thermocline depth anomalies within these composites, especially along the path of the ET inflow and, for cold years, on the western side of Pine Island Trough. All years of the composites show the same sign of change (indicated by stippling in Figs. $8 \mathrm{c}, \mathrm{d}$ ) across most of the continental shelf, with more extensive agreement for warm years. The sign of the thermocline depth changes in the CT region and along the shelf break are less consistent than for the ET region and within Pine Island Trough.

The CDW flux anomalies (Figs. 8a,b) follow a similar path to the time mean (Fig. 1), suggesting amplification 
(a) cold composite mean

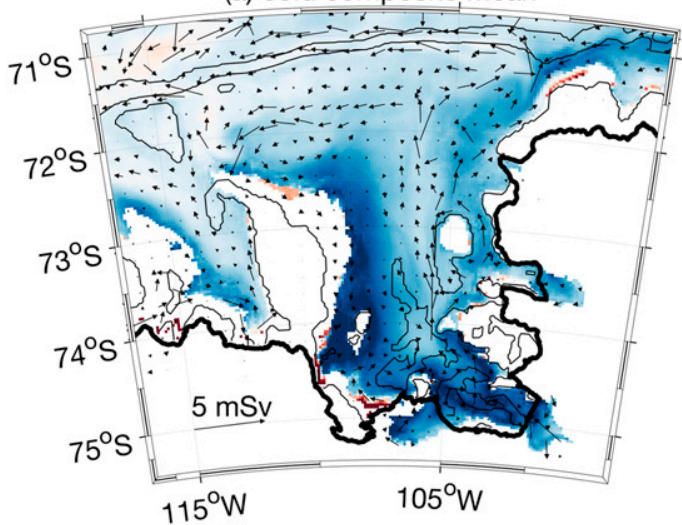

(b) warm composite mean
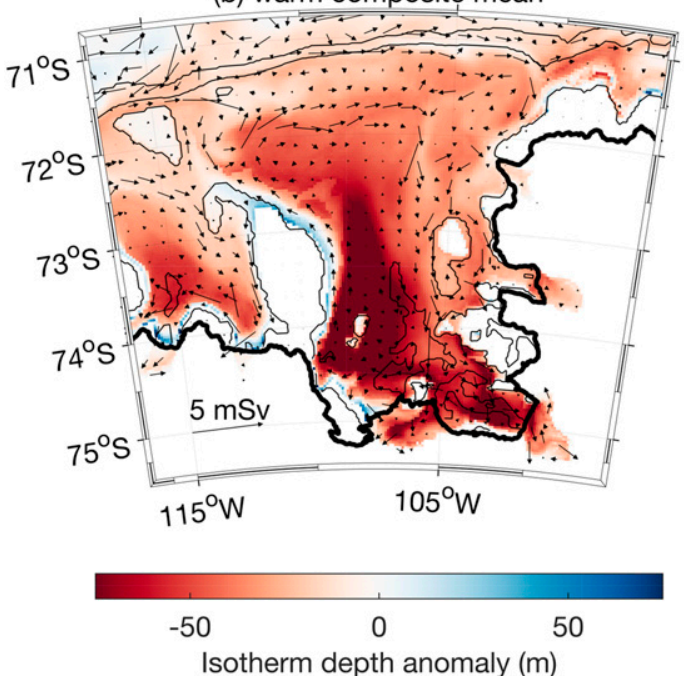

(c) cold composite STD

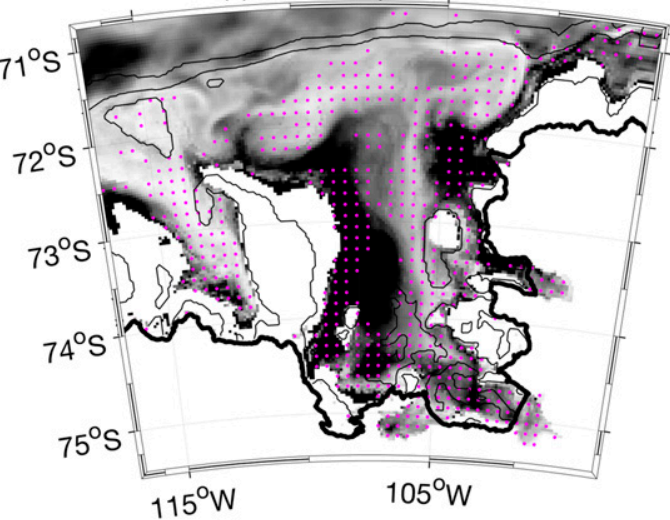

(d) warm composite STD

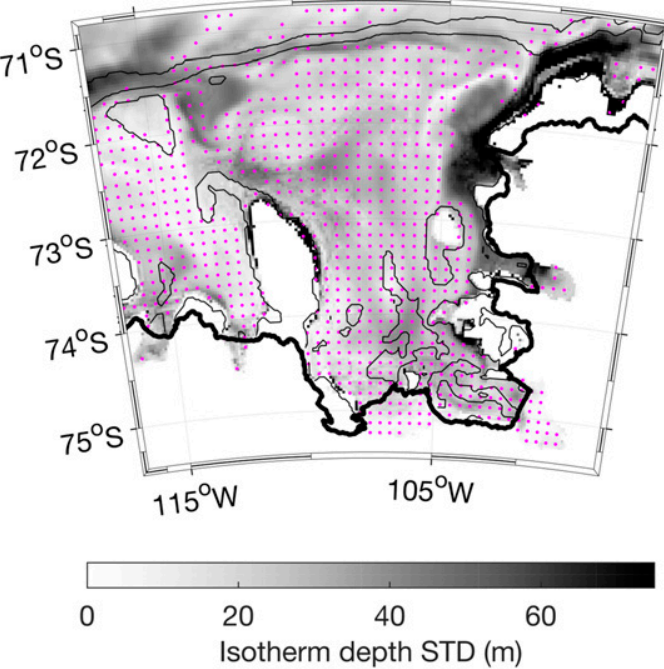

FIG. 8. Composite anomalies of $0.5^{\circ} \mathrm{C}$ isotherm depth $(\mathrm{m}$; shaded, see color bar) and volume flux of water warmer than $0.5^{\circ} \mathrm{C} \mathrm{(mSv}$; vectors; see scale) for (a) the five coldest years and (b) the five warmest years, as defined by the melt rate of PIG and Thwaites (Fig. 5f); (c),(d) the standard deviation (shaded) of the composite anomalies in (a) and (b), respectively; regions where all five years exhibit anomalies of the same sign are stippled. The thick black line denotes the coastline, while bathymetry is contoured as thin black lines at 500,1000, and $2000 \mathrm{~m}$.

and reduction of the time-mean pattern rather than a different circulation pattern, in disagreement with observations that suggest substantial changes in circulation patterns, at least within Pine Island Bay (Webber et al. 2017). The isotherm depth anomalies are more modest in the inflow region and at the shelf break than close to the glaciers. The thermocline depth anomalies along the shelf break (between the 1000- and 2000-m contours) are very weak, yet the volume flux anomalies are substantial and spatially coherent and show that the shelfedge undercurrent CDW transport (Walker et al. 2013) strengthens in warm years and weakens in cold years (Fig. 8). In general, the largest differences in isotherm depth are observed near the southern end of Pine Island Trough, possibly implying that processes close to the glacier amplify the signal that originates at the shelf break. We also note that the largest differences occur where the CDW flux is small (and deep velocity is weak; see Fig. 3), consistent with a volume flux balance where a small depth change in a region of strong flow is compensated by a larger depth change in a region of weaker flow.

To further examine the links between temperature transports across the shelf at all time scales, we use wavelet coherence (Grinsted et al. 2004) to assess the strength and phase of the relationships between the PIG section and each of the other sections in time-frequency space, using 5-day mean output. Figure 9 shows that the coherence is generally stronger at periods longer than 2 years, with coherence at periods less than 1 year only sporadically significant. The strongest coherence with the PIG section is for the (predominantly barotropic) temperature transport through MTE, perhaps unsurprising 

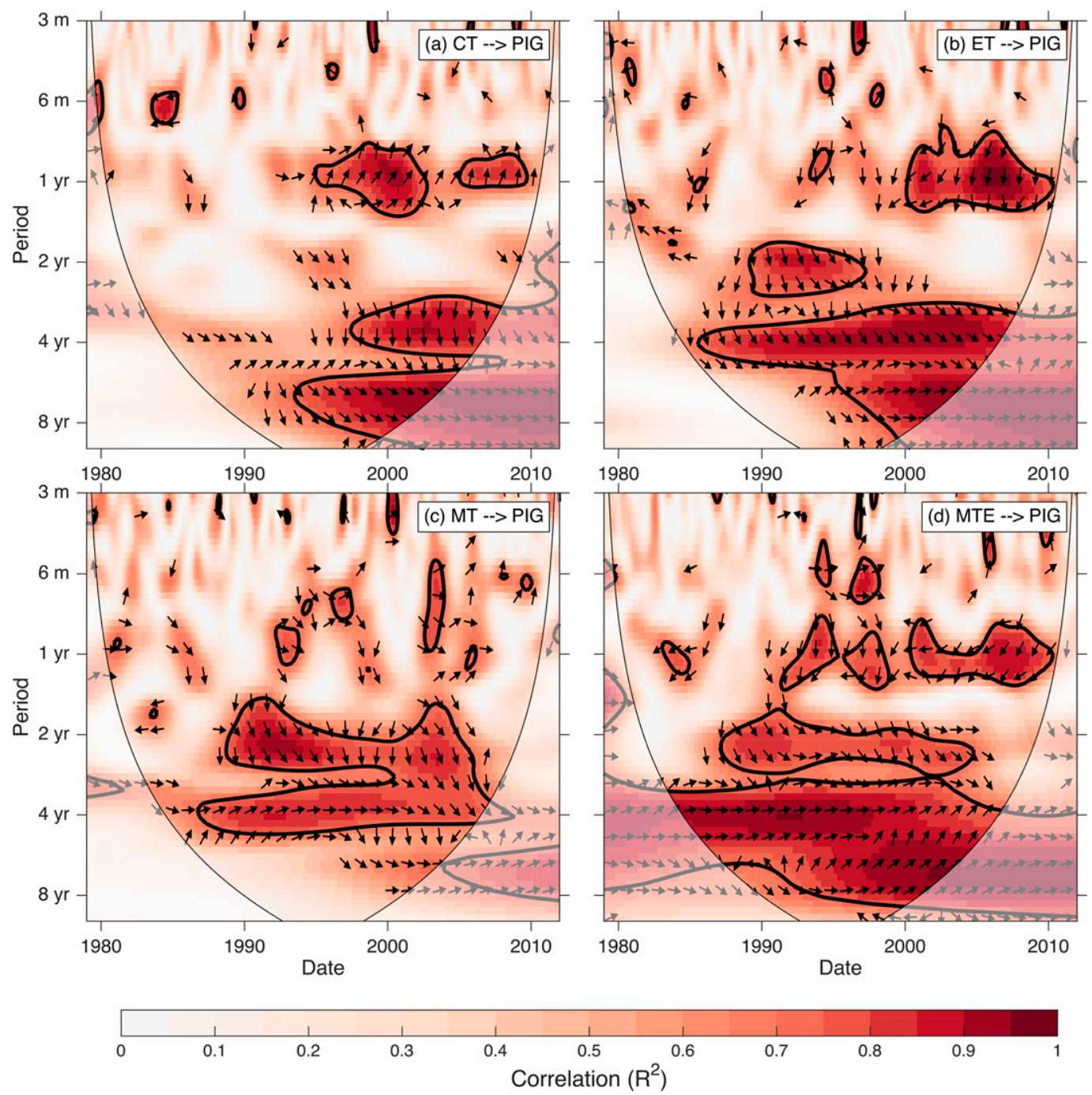

FIG. 9. Wavelet transform coherence between temperature transport through various sections and Pine Island Glacier at periods between 3 months and 10 years (note the logarithmic $y$ axis). (a) CT and PIG, (b) ET and PIG, (c) MT and PIG, and (d) MTE and PIG; see Fig. 1 for section locations. Shading indicates the correlation between the wavelet transforms, while the arrows indicate the phase relationship, such that arrows pointing downward (upward) indicate that the first time series leads (lags) the temperature transport through the PIG section, while rightward (leftward)-pointing arrows indicate the series are in (out of) phase. Regions of statistically significant correlation (at the $95 \%$ level) are indicated by the thick black lines.

given the relatively close proximity. The coherence is stronger with the ET section than the CT section. The phase relationships between time series is demonstrated by the arrows, with arrows pointing right (left) indicating the time series are in (out of) phase, while arrows pointing down (up) indicate that the first (second) time series leads the second (first) by one quarter of a cycle. These phase arrows indicate that the temperature transports at the shelf-break and midtrough sections generally lead the temperature transport through the PIG section, at lags between 6 months and 2 years, broadly consistent with the advective time scale from the shelf edge to the ice shelves of around 6-12 months. However, the coherence at these time scales is sporadic, which may explain why this connection is not readily apparent in the composites of warm and cold years (Fig. 8). Nakayama et al. (2017) used model tracers to show that concentrations of CDW in Pine Island Bay continue to increase up to two years after intrusion onto the continental shelf, consistent with the longer lags found here. At time scales longer than 4 years, the various time series are largely in phase, although PIG variability leads both the MTE and CT temperature transports at these longer time scales. 

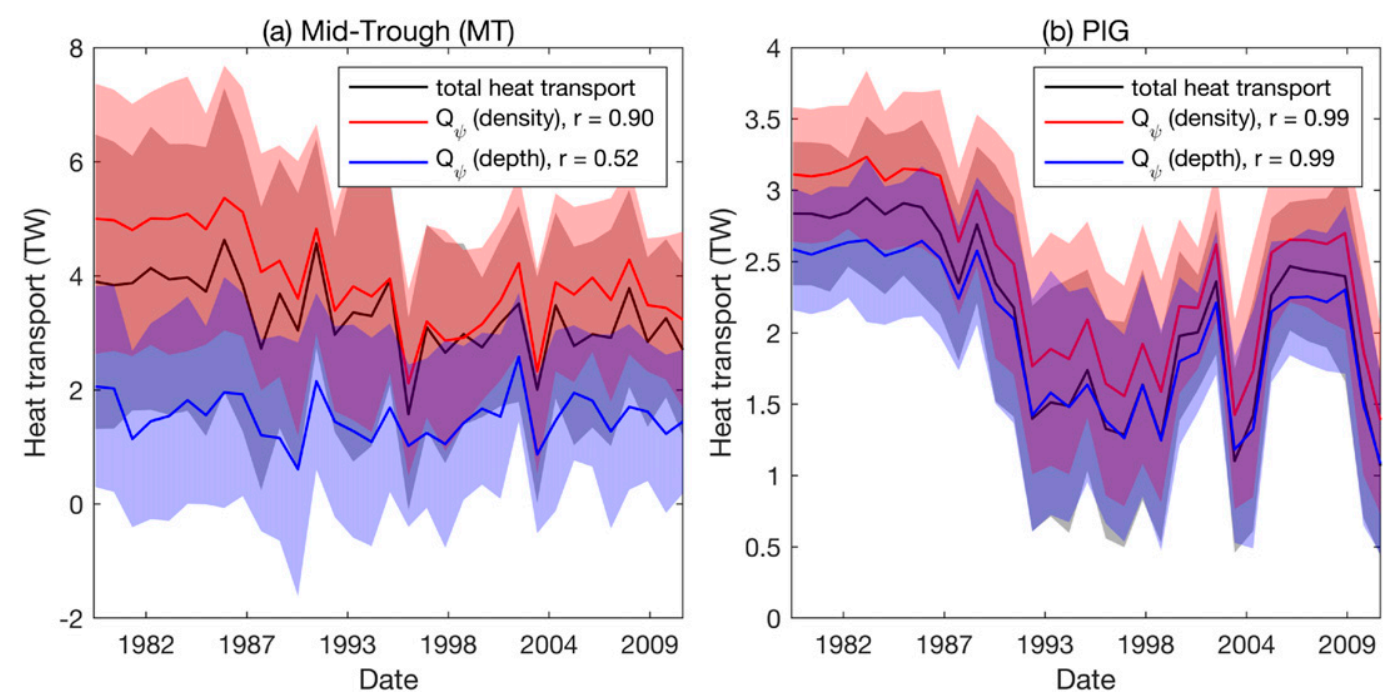

FIG. 10. Annual mean (lines) and annual standard deviation (shading) of temperature transport (TW) due to overturning circulation in depth (blue) and density (red) space, plus total temperature transport (black) for (a) MT and (b) PIG sections. The correlation coefficient between the total and the two overturning temperature transports is given in the legends for each panel.

\section{d. Temporal variability of overturning and CDW fluxes}

To investigate the temporal variability in the overturning strength, we calculate a time series of the peak (minimum) overturning streamfunction in density space at the latitude $\left(74.2^{\circ} \mathrm{S}\right)$ of the midtrough section (red line in Fig. 5f). The time series of peak overturning exhibits the same decadal variability as the temperature transport around the continental shelf and agrees strongly with the melt rate of PIG and Thwaites ice shelves (correlation coefficient $r=-0.88$ ). Similar results are obtained for the variability in overturning strength at various latitudes, implying that the interannual variability of the overturning is latitudinally consistent. The mean overturning strength in density space is $-0.38 \mathrm{~Sv}$; for comparison, the mean strength of the barotropic circulation through this section is $-2.0 \mathrm{~Sv}$.

The southward temperature transport associated with the overturning part of the circulation in density space (red lines in Fig. 10) closely matches the total temperature transport at the MT and PIG sections. This overturning temperature transport tends to exceed the total temperature transport as the isopycnal circulation is associated with a net negative (northward) temperature transport (not shown). Meanwhile, in depth space (blue lines in Fig. 10), the overturning temperature transport is very close to the total temperature transport at the PIG section but roughly half the total temperature transport at the MT section. This difference between the sections is consistent with the latitudinal variation in the overturning strength in depth space (Fig. 4a), while the overturning strength is more latitudinally consistent in density space. This implies that at the MT section, the outflow of colder, fresher, and less dense water overlaps in depth space with the inflow of warmer, saltier, and denser water. We note that the time series of the overturning temperature transport in density space at MT is well correlated $(r=0.90)$ with the melt rate of the Pine Island and Thwaites ice shelves, while the overturning temperature transport in depth space at MT is only weakly correlated $(r=0.40)$. Note that although the barotropic volume transport is larger than the overturning circulation, the net barotropic heat transport is much smaller than the heat transport associated with the overturning circulation.

The varying strength of the overturning circulation (Fig. 5f) is matched closely by the time series of volume flux of CDW (Fig. 11) through each of the sections; the correlation coefficient $r$ is $0.84,0.72,0.87$, and 0.98 between peak overturning strength and CDW flux for CT, ET, MT, and PIG, respectively. Very little CDW enters Pine Island Trough without first flowing through either the CT or ET section (see Fig. 1); therefore, the total CDW flux onto the continental shelf can be seen as the sum of these two. Once again, the temporal variability of the CDW flux through the CT, ET, and MTE (not shown) sections is very similar, suggesting that changes in the CDW flux onto the shelf translate into changes in the CDW flux farther south or possibly that changes in the melt-driven overturning influence the onshore transport of CDW. Interestingly, the total CDW flux 

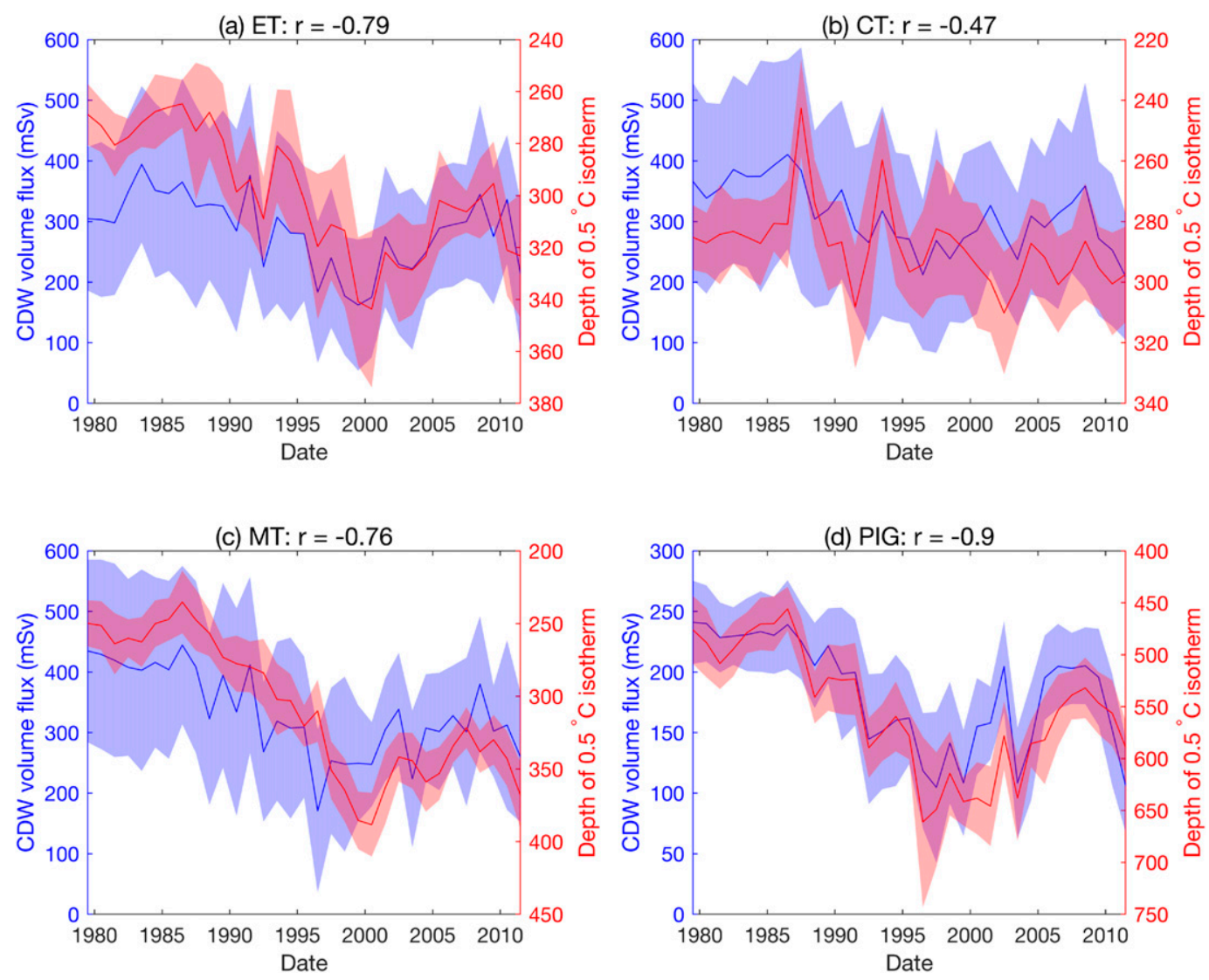

FIG. 11. Annual mean (line) and annual standard deviation (shading) of volume flux of CDW (water warmer than $0.5^{\circ} \mathrm{C}$; blue) and the depth of the $0.5^{\circ} \mathrm{C}$ isotherm (red), for the (a) ET, (b) CT, (c) MT, and (d) PIG sections. For each panel the correlation coefficient $r$ between the volume flux of CDW and the depth of the $0.5^{\circ} \mathrm{C}$ isotherm is given in the title.

through the closed sections (PIG and MT) also exhibits similar temporal variability. If the overturning circulation and the transformation of CDW into meltwater did not occur, the net CDW flux would be near zero. Instead, the net CDW flux through the MT section is more than half $(52 \%)$ the total that flows onto the shelf through the $\mathrm{CT}$ and ET sections, which jointly capture the majority of the CDW flowing onto the continental shelf. As the flux of CDW onto the shelf decreases, the heat available to melt the ice shelf decreases, leading to a corresponding decrease in water mass transformation and thus net CDW flux through the PIG and MT sections.

Variations in the flux of CDW can be due to changes in the thermocline depth, the velocity below the thermocline, or both. To determine which is the case in our model simulation, we examine the correlation between thermocline depth and CDW flux at each section. The temporal variability in thermocline depth is inversely correlated with the CDW flux (i.e., a shallower thermocline is related to a larger CDW flux) at the ET $(r=-0.79)$, MT $(r=-0.76)$, and PIG $(r=-0.90)$ sections. The minimum in thermocline depth lags the minimum in CDW flux at the MT section, possibly owing to an imbalance between net volume flux into the CDW layer in Pine Island Bay and water mass transformation within this region or owing to differences in local surface forcing. At the CT section, the thermocline depth is relatively poorly correlated $(r=-0.47)$ with the CDW flux, indicating that it is primarily the velocity in the CDW layer and not the depth of the CDW layer that controls the inflow of CDW here, while at the other sections a combination of the two factors controls the CDW volume flux.

\section{e. Mechanisms generating decadal variability in Pine Island Trough}

We investigate possible atmospheric forcing mechanisms by computing correlations between the annualmean melt rate of Pine Island and Thwaites ice shelves and the annual mean of various surface forcing fields for each model grid point. The ice shelf melt rate is correlated with easterly (negative) zonal surface stress (Fig. 12a) and 
(a) Zonal surface stress

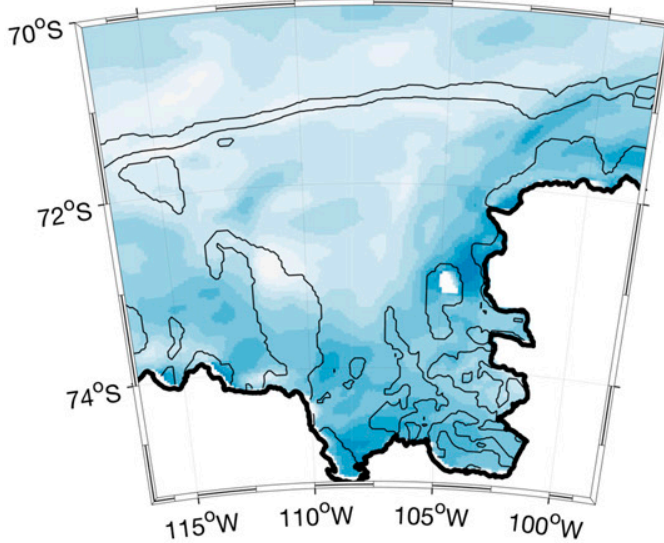

(c) Ekman upwelling

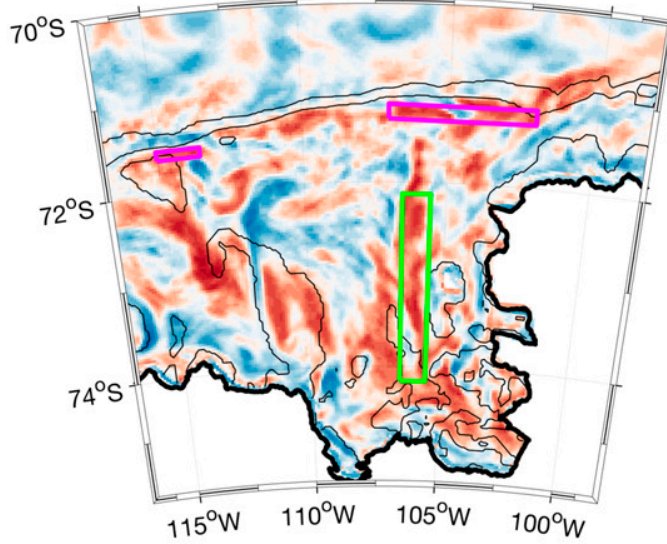

(e) Total surface stress

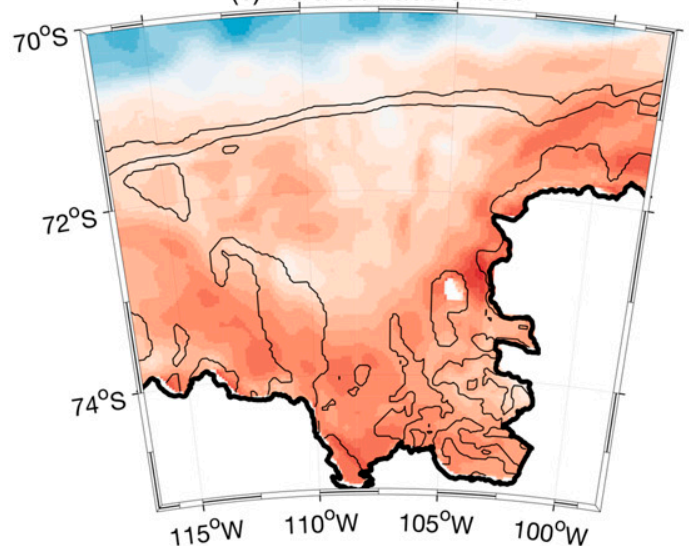

(b) Meridional surface stress

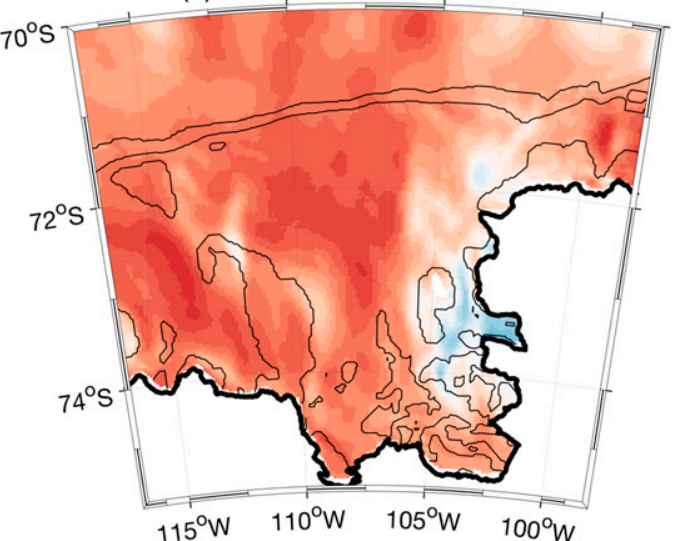

(d) Surface heat flux

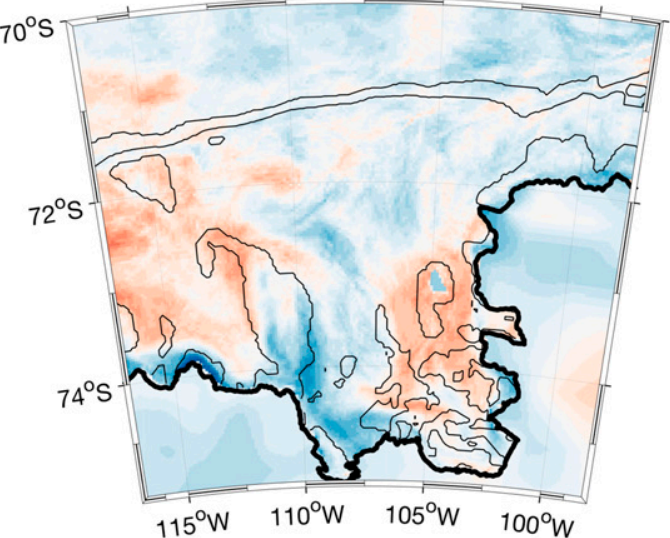

(f) Surface freshwater flux
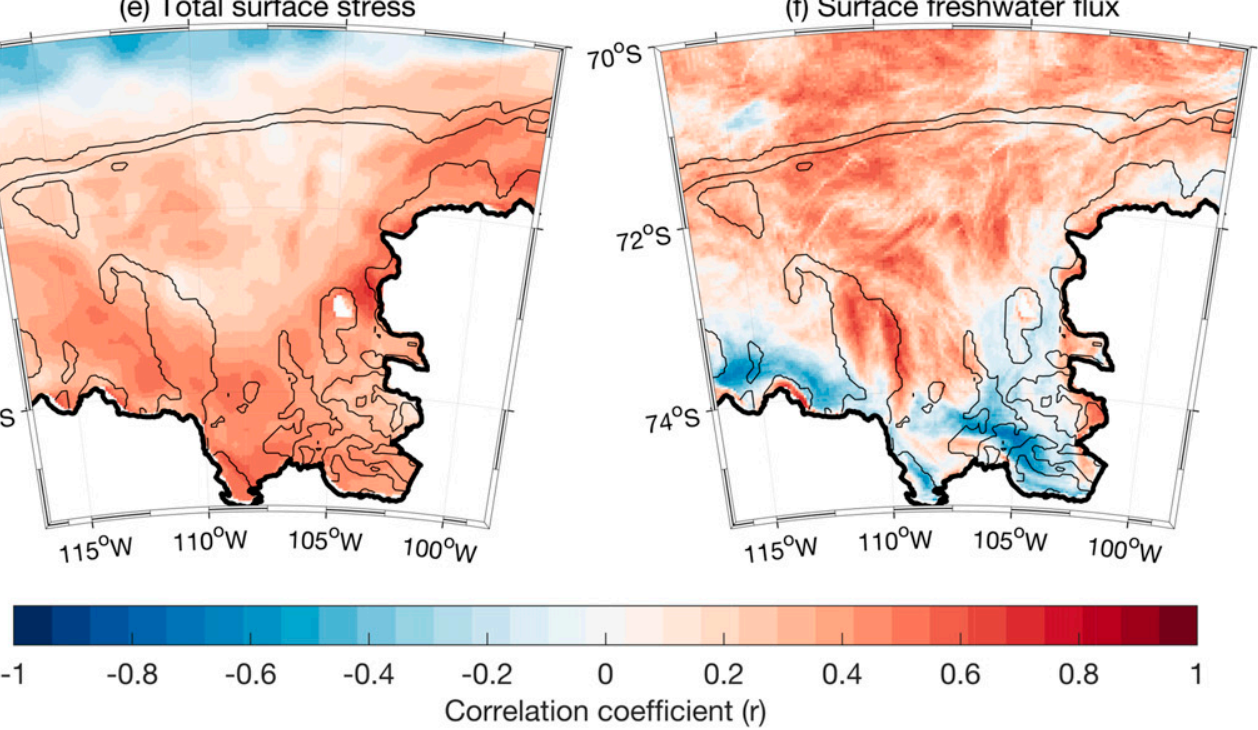

FIG. 12. Correlation coefficient between combined melt rate of PIG and Thwaites and (a) zonal surface stress, (b) meridional surface stress, (c) Ekman upwelling and (d) surface heat flux (positive into ocean), (e) total surface stress, and (f) surface freshwater flux (positive into ocean). The magenta and green boxes in (c) are used to derive the time series in Fig. 13. 
northward (positive) meridional surface stress (Fig. 12b) across the entire Pine Island Trough region that combine to give a large-scale increase in total surface stress (Fig. 12e). It may be that these offshore winds help to drive a surface current away from the ice shelves, thus strengthening the compensating influx of warm water below due to mass conservation. The curl of the surface stress suggests that upwelling across much of the shelf is correlated with increased melt rate. Upwelling along the shelf break (magenta boxes in Fig. 12c) is also correlated with increased melt and modulates the transport of CDW onto the shelf (Fig. 13). This change in CDW flux in turn appears to drive changes in ice shelf melt rate. Meanwhile, the minimum Ekman suction within Pine Island Trough is delayed relative to the minimum at the shelf break and the minimum in ice shelf melt rate. However, the minimum Ekman suction in Pine Island Trough does coincide with the maximum thermocline depth at the MT section and may therefore explain the lag of the thermocline depth relative to the CDW transport here (Fig. 11c). It is likely that Ekman suction is the dominant driver of the changes we observe, but internal ocean processes may also play a role in determining the decadal variability of this region.

Surface heat flux is negatively correlated with increased melt, especially close to the ice shelves. We interpret this as indicating that stronger overturning circulation supplies more oceanic heat to the near surface, thus increasing the air-sea temperature difference and the heat loss to the atmosphere and creating a negative feedback. The correlation between ice shelf melt rate and surface freshwater flux (Fig. 12f) is positive across much of the continental shelf, which may help raise the thermocline by reducing the density of the winter water layer. If that were a dominant mechanism, we would expect negative local correlations between surface freshwater flux and thermocline depth. However, the map of local correlation with thermocline depth (not shown) is simply the inverse of Fig. 12f, suggesting that the relationship is not as strong as the influence of wind stress on thermocline depth and hence ice shelf melt rate.

\section{Discussion}

We find that temperature transports and ice shelf melt rates covary across the Amundsen Sea and that both covary with the strength of the overturning circulation in Pine Island Trough. The time-mean southward barotropic volume transport at $\mathrm{MT}\left(74.2^{\circ} \mathrm{S}\right)$ is $2.0 \mathrm{~Sv}$, much larger than the volume transport associated with the density overturning circulation $(0.38 \mathrm{~Sv})$. However, the net barotropic temperature transport through this
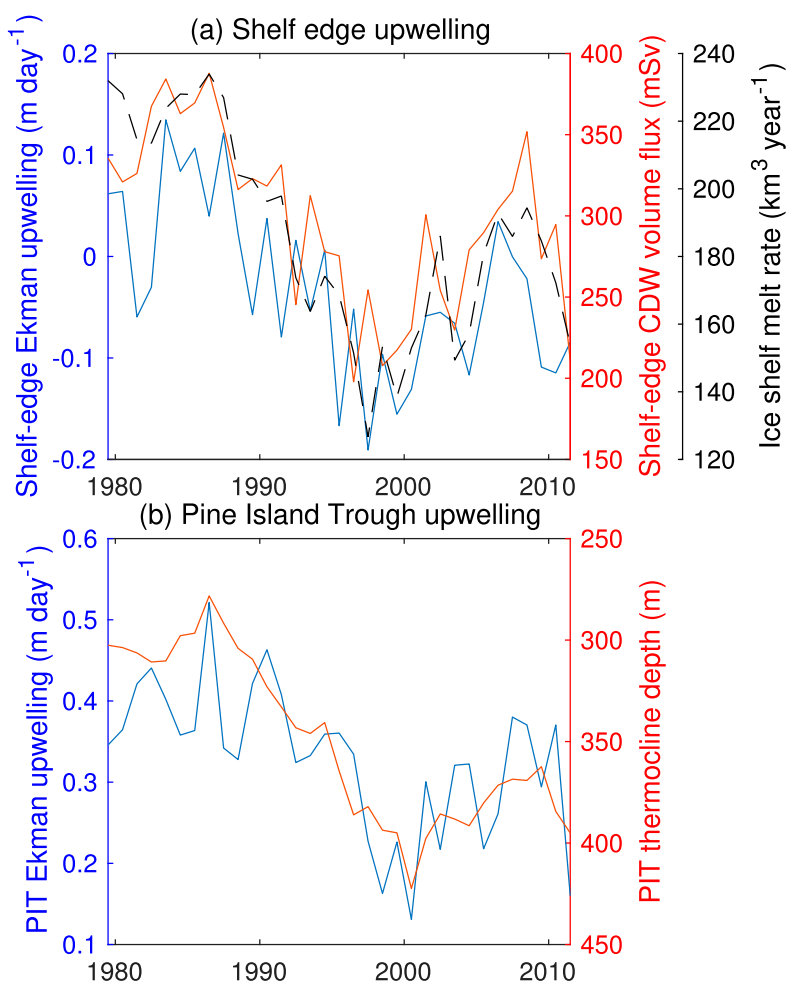

FIG. 13. (a) Time series of area-mean Ekman upwelling in the two magenta boxes shown in Fig. 12c (blue line); mean CDW volume flux through CT and ET sections (red line) and melt rate of Pine Island and Thwaites ice shelves (black dashed line). (b) Areamean Ekman upwelling in the green box shown in Fig. 12c (blue line); mean thermocline depth for the MT section (red line).

closed section is small, and the overturning circulation in density space is responsible for most of the net southward temperature transport through this section and into Pine Island Bay. Farther north, the transport of temperature onto the continental shelf is primarily barotropic. Since the time series of (barotropic) on-shelf transport and the overturning farther south are highly correlated, and both correlate with the ice shelf melt rate, it is not possible to determine which is more important for the ice shelf melt rate.

Given that the overturning circulation drives the majority of the net heat transport and is in turn driven by melting of the ice shelves, it is possible that there is a positive feedback whereby an increase in melting drives an increase in overturning that in turn increases the melt further, such as shown by Donat-Magnin et al. (2017) and Jourdain et al. (2017). Donat-Magnin et al. (2017) show that this can also lead to an increase in the onshore flux of CDW. This would be a two-way process, in which heat-driven melt and melt-driven temperature transport are occurring.

Surface wind forcing directly influences the variability of heat transport in Pine Island Trough. In warm years, 
the pattern of Ekman suction at the shelf break increases the onshore flux of CDW. Ekman-induced upwelling farther onshore will amplify the changes in thermocline depth, consistent with the larger amplitude of thermocline depth variability there. These changes may be further amplified by offshore winds during warm years. Changes in both circulation and the thickness of the CDW layer will influence the melt rate of the ice shelves. Together, these findings suggest that changes in the deep inflow of heat and CDW are directly influenced by wind stress and wind stress curl, which then lead to changes in melt rate and thermocline depth.

The decadal melt rate variability is associated with broadscale and spatially coherent changes in CDW transport and thermocline depth, strongest close to the ice shelves and on the western side of Pine Island Trough. Observational records across the Amundsen Sea do not always show such clear covariability between the shelf edge and Pine Island Bay (Webber et al. 2017). The discrepancy may be due to the relatively short observational records, the relatively coarse model resolution, or the poor simulation of atmospheric processes close to the coast in the reanalysis products used to force the ocean models, where high heat flux events that lead to cooling within Pine Island Bay are underrepresented (Jones et al. 2016). Alternatively, it could be that the model thermocline being too shallow leads to an overestimate of the strength of the relationship between the continental shelf edge and Pine Island Bay. Further mechanism-denial experiments with this or other models would be required to resolve this.

We note that several of our sections are associated with large net volume transports and that the total temperature transport is dependent on the subjective choice of end points for these sections (Schauer and Beszczynska-Möller 2009). We have chosen the open sections to correspond to the main inflows of CDW onto the shelf (CT and ET) and southward into Pine Island Bay (MTE). Nevertheless, the magnitude of the total temperature transport through these sections is somewhat arbitrary and would change depending on the exact definitions of the sections. Furthermore, the split between thermodynamic $\left(v^{\prime} \bar{T}\right)$ and kinematic $\left(\bar{v} T^{\prime}\right)$ temperature transport variability and the split between baroclinic and barotropic temperature transport may be sensitive to the choice of section, although sensitivity studies (not shown) suggest that small changes make a negligible difference to the conclusions. Nevertheless, our findings are most robust for the closed MT and PIG sections with near-zero net volume transport.

Our model may not fully resolve small-scale processes including eddies, internal waves, and the interaction of ocean dynamics with small-scale topographic features that may influence the dynamics of the temperature transport and overturning. In addition, the bathymetry of the region is poorly mapped in many places, and that may lead to substantial biases in temperature transport pathways and variability. Our model has a thermocline that is too shallow and with a density gradient that is too small compared with observations, leading to melt rates that exceed observed values. Because of uncertainties in reanalysis products used to force ocean models (due largely to the sparse meteorological observations) and the lack of ocean observations to validate the model before 1994, it is hard to be certain of the true decadal variability in this region, and various ocean model simulations of the region (e.g., Thoma et al. 2008; Schodlok et al. 2012; Nakayama et al. 2013; Kimura et al. 2017) produce markedly different time series. However, the model simulation presented here has been shown to reproduce the variability in Pine Island Trough within the period of 1994-2011 for which observations are available. It is harder to be sure of whether the relatively warm period in the 1980s and subsequent cooling in the early 1990s is realistic or not, although the steady increase in ice shelf mass loss over this period (Mouginot et al. 2014) would be more consistent with overall warming. We note that our model does not have adaptive ice shelves, which would tend to alter the melt rate as the cavity geometry changes (Schodlok et al. 2012) and might then influence the circulation around Pine Island Trough. Also, the boundary conditions for our model are a repeated annual cycle so decadal changes in the far-field ocean conditions are not captured.

Although our model is overly warm and has climatological boundary conditions and uncertainties in the surface forcing, we argue that the importance of the Ekman upwelling and the predominance of the overturning circulation in providing the net southward heat transport are robust results. However, it is possible that unresolved processes close to the ice shelves and the fixed ice shelf cavities mean that the model overestimates the true coherence between the onshore transport of heat and the melt rate of the ice shelves.

\section{Summary}

We have shown that melt rates and onshore CDW transports covary over large parts of the continental shelf at interannual to decadal time scales, but it is not possible from this study to determine which drives which, or if a third process drives both. The dominant external forcing mechanism for this variability is Ekman pumping and suction on the continental shelf and at the shelf break, in agreement with previous studies (e.g., Thoma et al. 2008; Kimura et al. 2017). At the continental shelf break, the southward transport of CDW and 
heat is predominantly barotropic. Farther south within Pine Island Trough, northward and southward barotropic heat transports largely cancel, and the majority of the net southward temperature transport is facilitated by baroclinic and overturning circulations. The overturning circulation is related to water mass transformation and buoyancy gain on the shelf that is primarily facilitated by freshwater input from basal melting. Donat-Magnin et al. (2017) and Jourdain et al. (2017) showed the existence of feedback mechanisms in which increased melt in turn may intensify the overturning circulation. Given the importance of the overturning circulation for heat transport, it is likely that a feedback exists in which both heat-driven melt and melt-driven temperature transport are occurring. However, this internal process will be modified by external forcing by surface wind stress and Ekman pumping. Understanding how such feedbacks would influence the long-term variability of the Amundsen Sea is an important challenge in the context of disentangling climate change from natural variability in this region.

Acknowledgments. BGMW, KJH, and DPS were supported by funding from the U.K. Natural Environment Research Council's iSTAR Programme through NERC Grant NE/J005703/1. The authors thank two anonymous reviewers for comments that helped greatly improve the manuscript. The authors thank Sudipta Goswami for performing the numerical model simulations. The analysis presented in this paper was carried out on the High Performance Computing Cluster supported by the Research and Specialist Computing Support service at the University of East Anglia. The data used in this manuscript are available from the corresponding author on reasonable request.

\section{REFERENCES}

Antonov, J. I., and Coauthors, 2010: Salinity. Vol. 2, World Ocean Atlas 2009, NOAA Atlas NESDIS 68, 184 pp.

Arneborg, L., A. K. Wåhlin, G. Björk, B. Liljebladh, and A. H. Orsi, 2012: Persistent inflow of warm water onto the central Amundsen shelf. Nat. Geosci., 5, 876-880, https://doi.org/ 10.1038/ngeo1644.

Assmann, K. M., A. Jenkins, D. R. Shoosmith, D. P. Walker, S. S. Jacobs, and K. W. Nicholls, 2013: Variability of circumpolar deep water transport onto the Amundsen Sea Continental shelf through a shelf break trough. J. Geophys. Res. Oceans, 118, 6603-6620, https://doi.org/10.1002/2013JC008871.

Biddle, L. C., K. J. Heywood, J. Kaiser, and A. Jenkins, 2017: Glacial meltwater identification in the Amundsen Sea. J. Phys. Oceanogr., 47, 933-954, https://doi.org/10.1175/JPO-D-160221.1.

Bindschadler, R., D. G. Vaughan, and P. Vornberger, 2011: Variability of basal melt beneath the PIG ice shelf, West Antarctica. J. Glaciol., 57, 581-595, https://doi.org/10.3189/ 002214311797409802.
Christianson, K., and Coauthors, 2016: Sensitivity of Pine Island Glacier to observed ocean forcing. Geophys. Res. Lett., 43, 10 817-10 825, https://doi.org/10.1002/2016GL070500.

Donat-Magnin, M., N. C. Jourdain, P. Spence, J. Le Sommer, H. Gallée, and G. Durand, 2017: Ice-shelf melt response to changing winds and glacier dynamics in the Amundsen Sea sector, Antarctica. J. Geophys. Res. Oceans, 122, $10206-$ 10 224, https://doi.org/10.1002/2017JC013059.

Dutrieux, P., and Coauthors, 2014: Strong sensitivity of Pine Island ice-shelf melting to climatic variability. Science, $\mathbf{3 4 3}, 174-178$, https://doi.org/10.1126/science.1244341.

Favier, L., and Coauthors, 2014: Retreat of Pine Island Glacier controlled by marine ice-sheet instability. Nat. Climate Change, 4, 117-121, https://doi.org/10.1038/nclimate2094.

Grinsted, A., J. C. Moore, and S. Jevrejeva, 2004: Application of the cross wavelet transform and wavelet coherence to geophysical time series. Nonlinear Processes Geophys., 11, 561566, https://doi.org/10.5194/npg-11-561-2004.

Heywood, K., and Coauthors, 2016: Between the devil and the deep blue sea: The role of the Amundsen Sea continental shelf in exchanges between ocean and ice shelves. Oceanography, 29, 118-129, https://doi.org/10.5670/oceanog.2016.104.

Holland, P. R., 2017: The transient response of ice shelf melting to ocean change. J. Phys. Oceanogr., 47, 2101-2114, https://doi. org/10.1175/JPO-D-17-0071.1.

Jacobs, S. S., A. Jenkins, C. F. Giulivi, and P. Dutrieux, 2011: Stronger ocean circulation and increased melting under Pine Island Glacier ice shelf. Nat. Geosci., 4, 519-523, https://doi. org/10.1038/ngeo1188.

Jenkins, A., P. Dutrieux, S. Jacobs, E. Steig, H. Gudmundsson, J. Smith, and K. Heywood, 2016: Decadal ocean forcing and Antarctic Ice Sheet response: Lessons from the Amundsen Sea. Oceanography, 29, 106-117, https://doi.org/10.5670/ oceanog.2016.103.

Jones, R. W., I. A. Renfrew, A. Orr, B. G. M. Webber, D. M. Holland, and M. A. Lazzara, 2016: Evaluation of four global reanalysis products using in situ observations in the Amundsen Sea Embayment, Antarctica. J. Geophys. Res. Atmos., 121, 6240-6257, https://doi.org/10.1002/2015JD024680.

Jourdain, N. C., P. Mathiot, N. Merino, G. Durand, J. Le Sommer, P. Spence, P. Dutrieux, and G. Madec, 2017: Ocean circulation and sea-ice thinning induced by melting ice shelves in the Amundsen Sea. J. Geophys. Res. Oceans, 122, 2550-2573, https://doi.org/10.1002/2016JC012509.

Kalén, O., K. M. Assmann, A. K. Wåhlin, H. K. Ha, T. W. Kim, and S. H. Lee, 2016: Is the oceanic heat flux on the central Amundsen Sea shelf caused by barotropic or baroclinic currents? Deep-Sea Res. II, 123, 7-15, https://doi.org/10.1016/ j.dsr2.2015.07.014.

Kimura, S., and Coauthors, 2017: Oceanographic controls on the variability of ice-shelf basal melting and circulation of glacial meltwater in the Amundsen Sea Embayment, Antarctica. J. Geophys. Res. Oceans, 122, 10131-10155, https://doi.org/ 10.1002/2017JC012926.

Locarnini, R. A., A. V. Mishonov, J. I. Antonov, T. P. Boyer, H. E. Garcia, O. K. Baranova, M. M. Zweng, and D. R. Johnson, 2010: Temperature. Vol. 1, World Ocean Atlas 2009, NOAA Atlas NESDIS 68, 184 pp.

Losch, M., 2008: Modeling ice shelf cavities in a z coordinate ocean general circulation model. J. Geophys. Res., 113, C08043, https://doi.org/10.1029/2007JC004368.

, D. Menemenlis, J. M. Campin, P. Heimbach, and C. Hill, 2010: On the formulation of sea-ice models. Part 1: Effects of 
different solver implementations and parameterizations. Ocean Modell., 33, 129-144, https://doi.org/10.1016/j.ocemod.2009.12.008.

Mallett, H., L. Boehme, M. Fedak, K. J. Heywood, D. Stevens, and F. Roquet, 2018: Variation in the distribution and properties of Circumpolar Deep Water in the eastern Amundsen Sea, on seasonal timescales, using seal-borne tags. Geophys. Res. Lett., 45, 4982-4990, https://doi.org/10.1029/2018GL077430.

Marshall, J., A. Adcroft, C. Hill, L. Perelman, and C. Heisey, 1997: A finite-volume, incompressible Navier Stokes model for studies of the ocean on parallel computers. J. Geophys. Res., 102, 5753-5766, https://doi.org/10.1029/96JC02775.

Mouginot, J., E. Rignot, and B. Scheuchl, 2014: Sustained increase in ice discharge from the Amundsen Sea Embayment, West Antarctica, from 1973 to 2013. Geophys. Res. Lett., 41, 15761584, https://doi.org/10.1002/2013GL059069.

Nakayama, Y., M. Schröder, and H. H. Hellmer, 2013: From circumpolar deep water to the glacial meltwater plume on the eastern Amundsen Shelf. Deep-Sea Res., 77, 50-62, https://doi. org/10.1016/j.dsr.2013.04.001.

— , R. Timmermann, C. B. Rodehacke, M. Schröder, and H. H. Hellmer, 2014a: Modeling the spreading of glacial meltwater from the Amundsen and Bellingshausen Seas. Geophys. Res. Lett., 41, 7942-7949, https://doi.org/10.1002/2014GL061600.

,,-- M. Schröder, and H. H. Hellmer, 2014b: On the difficulty of modeling Circumpolar Deep Water intrusions onto the Amundsen Sea continental shelf. Ocean Modell., 84, 2634, https://doi.org/10.1016/j.ocemod.2014.09.007.

_ D. Menemenlis, M. Schodlok, and E. Rignot, 2017: Amundsen and Bellingshausen Seas simulation with optimized ocean, sea ice, and thermodynamic ice shelf model parameters. J. Geophys. Res. Oceans, 122, 6180-6195, https://doi.org/ 10.1002/2016JC012538.

Rahmstorf, S., J. E. Box, G. Feulner, M. E. Mann, A. Robinson, S. Rutherford, and E. J. Schaffernicht, 2015: Exceptional twentieth-century slowdown in Atlantic Ocean overturning circulation. Nat. Climate Change, 5, 475-480, https://doi.org/ 10.1038/nclimate2554.

Rignot, E., S. S. Jacobs, J. Mouginot, and B. Scheuchl, 2013: Iceshelf melting around Antarctica. Science, 341, 266-270, https:// doi.org/10.1126/science.1235798.

Saha, S., and Coauthors, 2010: The NCEP Climate Forecast System Reanalysis. Bull. Amer. Meteor. Soc., 91, 1015-1057, https:// doi.org/10.1175/2010BAMS3001.1.

Schauer, U., and A. Beszczynska-Möller, 2009: Problems with estimation and interpretation of oceanic heat transport: Conceptual remarks for the case of Fram Strait in the Arctic Ocean. Ocean Sci., 5, 487-494, https://doi.org/10.5194/os-5-487-2009.
Schodlok, M. P., D. Menemenlis, E. Rignot, and M. Studinger, 2012: Sensitivity of the ice-shelf/ocean system to the sub-iceshelf cavity shape measured by NASA IceBridge in Pine Island Glacier, West Antarctica. Ann. Glaciol., 53, 156-162, https://doi.org/10.3189/2012AoG60A073.

$\longrightarrow,-$ _ and E. J. Rignot, 2016: Ice shelf basal melt rates around Antarctica from simulations and observations. J. Geophys. Res. Oceans, 121, 1085-1109, https://doi.org/10.1002/2015JC011117.

Snow, K., D. N. Goldberg, P. R. Holland, J. R. Jordan, R. J. Arthern, and A. Jenkins, 2017: The response of ice sheets to climate variability. Geophys. Res. Lett., 44, 11 878-11 885, https://doi.org/ 10.1002/2017GL075745.

Steig, E. J., Q. Ding, D. S. Battisti, and A. Jenkins, 2012: Tropical forcing of Circumpolar Deep Water Inflow and outlet glacier thinning in the Amundsen Sea Embayment, West Antarctica. Ann. Glaciol., 53, 19-28, https://doi.org/10.3189/2012AoG60A110.

St-Laurent, P., J. M. Klinck, and M. S. Dinniman, 2015: Impact of local winter cooling on the melt of Pine Island Glacier, Antarctica. J. Geophys. Res. Oceans, 120, 6718-6732, https:// doi.org/10.1002/2015JC010709.

Thoma, M., A. Jenkins, D. M. Holland, and S. S. Jacobs, 2008: Modelling Circumpolar Deep Water intrusions on the Amundsen Sea continental shelf, Antarctica. Geophys. Res. Lett., 35, L18602, https://doi.org/10.1029/2008GL034939.

Thurnherr, A. M., S. S. Jacobs, P. Dutrieux, and C. F. Giulivi, 2014: Export and circulation of ice cavity water in Pine Island Bay, West Antarctica. J. Geophys. Res. Oceans, 119, 1754-1764, https://doi.org/10.1002/2013JC009307.

Timmermann, R., and Coauthors, 2010: A consistent dataset of Antarctic ice sheet topography, cavity geometry, and global bathymetry. Earth Syst. Sci. Data., 2, 261-273, https://doi.org/ 10.5194/essd-2-261-2010.

Wåhlin, A. K., and Coauthors, 2013: Variability of warm deep water inflow in a submarine trough on the Amundsen Sea Shelf. J. Phys. Oceanogr., 43, 2054-2070, https://doi.org/10.1175/ JPO-D-12-0157.1.

Walker, D. P., M. A. Brandon, A. Jenkins, J. T. Allen, J. A. Dowdeswell, and J. Evans, 2007: Oceanic heat transport onto the Amundsen Sea shelf through a submarine glacial trough. Geophys. Res. Lett., 34, L02602, https://doi.org/10.1029/2006GL028154.

—, A. Jenkins, K. M. Assmann, D. R. Shoosmith, and M. A. Brandon, 2013: Oceanographic observations at the shelf break of the Amundsen Sea, Antarctica. J. Geophys. Res. Oceans, 118, 2906-2918, https://doi.org/10.1002/jgrc.20212.

Webber, B. G. M., and Coauthors, 2017: Mechanisms driving variability in the ocean forcing of Pine Island Glacier. Nat. Commun., 8, 14507, https://doi.org/10.1038/ncomms14507. 